\title{
A Novel Method for Quantifying Helmeted Field of View of a Spacesuit - And What It Means for Constellation
}

\author{
Shane M McFarland \\ MEI Technologies
}

Copyright (c) 2010 AIAA

\begin{abstract}
Field of view has always been a design feature paramount to helmet design, and in particular spacesuit design, where the helmet must provide an adequate field of view for a large range of activities, environments, and body positions. Historically, suited field of view has been evaluated either qualitatively in parallel with design or quantitatively using various test methods and protocols. As such, oftentimes legacy suit field of view information is either ambiguous for lack of supporting data or contradictory to other field of view tests performed with different subjects and test methods.
\end{abstract}

This paper serves to document a new field of view testing method that is more reliable and repeatable than its predecessors. It borrows heavily from standard ophthalmologic field of vision tests such as the Goldmann kinetic perimetry test, but is designed specifically for evaluating field of view of a spacesuit helmet. In this test, four suits utilizing three different helmet designs were tested for field of view. Not only do these tests provide more reliable field of view data for legacy and prototype helmet designs, they also provide insight into how helmet design impacts field of view and what this means for the Constellation Project spacesuit helmet, which must meet stringent field of view requirements that are more generous to the crewmember than legacy designs.

\section{INTRODUCTION}

Field of view [FOV] is a naturally driving factor in helmet design. Be it a motorcycle, military, deep-sea diving, racing, or spacesuit helmet, an adequate field of view is required to afford the wearer enough vision to the external environment to facilitate optimal performance. Naturally every helmet is designed differently with a unique set of tasks in mind. In auto racing, peripheral field of view may be extremely important; however, superior field of view may be less significant. In this example of a racing helmet, it is optimized for a very limited range of tasks, in a limited set of environments, and used by the wearer in only a small set of body positions.
The helmet in a spacesuit is somewhat unique in that the task set required of it, the environments in which it is used, and the body positions of the wearer, are myriad, and therefore, a field of view must be chosen that is sufficient for all of these conditions.

Equally important to designing a helmet with an adequate field of view is the process by which this field of view is tested and verified. While a subjective evaluation of helmeted field of view independently and against the relevant environments (cockpit, egress paths, surface and microgravity extra-vehicular activity [EVA] analogs) is a vital and essential checkpoint in the design process, it is also necessary to quantify the field of view using a reliable measuring technique. Not only does this direct measurement provide a means for verifying the field of view requirements, but it also provides a mechanism for comparing one suit or helmet's field of view to another, and for quantifying the sensitivity of this field of view to variables such as body position, suit pressure, and head size, shape and rotation.

\section{HISTORY}

There have been various test methods used to evaluate pressure suit field of view in the past. Early tests were very rudimentary and primarily employed static or moving markers on the wall, floor, or cockpit that corresponded to specific field of view angles from the point in space designated as the "eyepoint" (1). A data sheet from one of these tests is shown in Figure 1.

For the past several decades at NASA, a rather clever method has been used which consists of a marker on a rope that enters the test subject's visual field by means of a pulley system $(2,3)$. While this method is adequate at measuring the field of view of a helmet, there are some drawbacks.

- It is very difficult to evaluate any body position other than recumbent

- The test setup is unwieldy (although portable) and prone to variability due to manual operation

- The testing process is tedious, as there is no easy way to record each data point other than manual measurement 


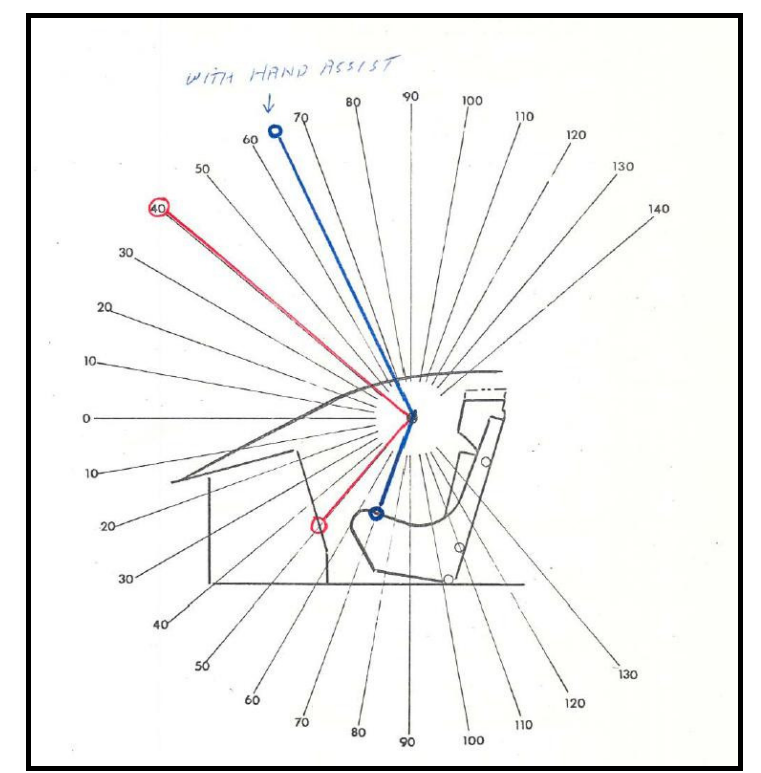

Figure 1: Pressure Suit Visibility Test, circa 1980

In addition, the tests performed at NASA using this method have not been done in a consistent, repeatable manner as there were many variables that were either not tested, or fixed but not specified.

- Subject anthropometric data

- Allowance for multiple subjects

- Variability due to body position

- Variability due to head or eye movement

- Marker size, color and speed

- Light conditions

- Limited field of view testing directions

- Limited sample size for statistical significance

In vision tests like these, it is most important to document the marker properties, as the size, speed and color of the marker can have a large impact on the perceived field of view. While these drawbacks do limit the completeness and value of previously collected field of view data, it should not be overlooked that these recent test methods do demonstrate recognition of the value in testing the kinematic field of view as opposed to the static field of view.

\section{FIELD OF VISION IN OPHTHAMOLOGY}

There are various methods used to test field of view, or field of vision as it termed by ophthalmologists. One of the most common is the Goldmann kinetic perimetry test. In this test, the subject sits with their head fixed in a stand. This stand places the eyes at the center of a hemispherical dome, onto which various sized light markers are moved into the visual field. When the subject sees the marker, they hit a button which records the viewing angle. Not only is this test method employed to measure the limits of a patient's field of vision, but it is also used to map blind spots and diagnose visual abnormalities such as cataracts (4). The Goldmann Perimeter hardware is shown in Figure 2.

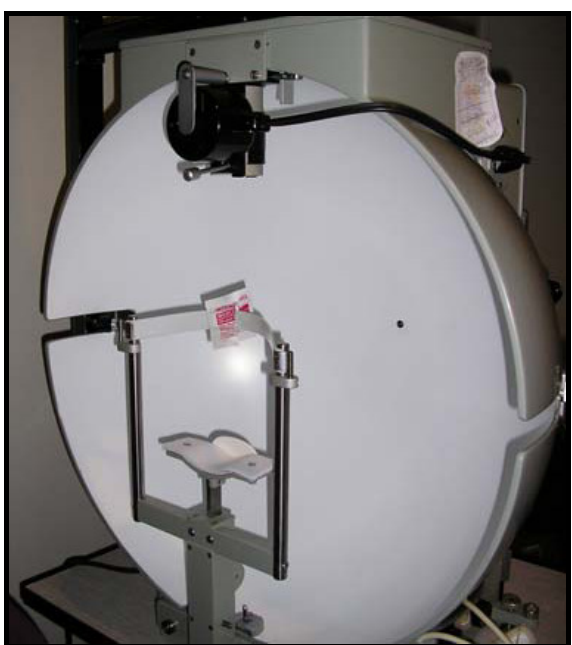

Figure 2: Goldmann Perimetry Test

The primary advantage of employing kinetic perimetry to evaluate visual fields is that $30 \%$ of patients with pathology cannot be tested with a static test; in addition, a kinetic test shows substantially less variability than a static test (4). Lastly, due to the construction of the human eye, which relies on rods for most of the vision outside of the central visual field, our peripheral vision is much more sensitive to motion and light, making a kinetic test necessary to truly test the outer bounds of the visual field (5).

An ideal method of testing helmet field of view would be to borrow as much from this standardized, medical exam as possible, which has shown to provide accurate and repeatable results for testing visual fields.

\section{TEST OBJECTIVES AND REQUIREMENTS}

The current Constellation program field of view requirement calls out five different field of view angles:

- A: Superior (up)

- B: Superior temporal (up and to the side)

- C: Temporal (to the side, also known as "peripheral")

- D: Inferior temporal (down and to the side)

- E: Inferior (down)

These five angles are shown below in Figure 3.

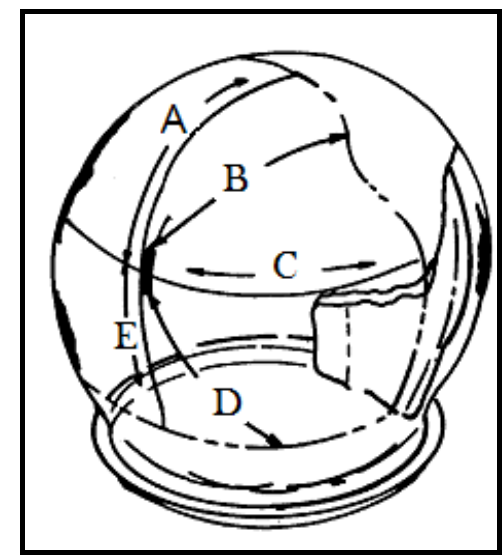

Figure 3: Five Field of View Angles 
As such, these five angles (or eight, if you consider asymmetry of the angles B, C, and D per Figure 3 above) are, at minimum, the angles requiring measurement.

Similarly, the Constellation requirement, which is shown below in Table 1, calls for six different fields of view depending on what segment of a mission the crewmember is in, and therefore entails a specific suit/helmet configuration, body position, etc (6). As such, it is necessary to provide functionality to test field of view in different body positions, which is something historically difficult from previous field of view tests.

Lastly, an electronic method for collecting, manipulating, and recording data was highly desirable. Not only would this make tests more efficient and accurate, but it would allow for a larger sample size in the same period of time.

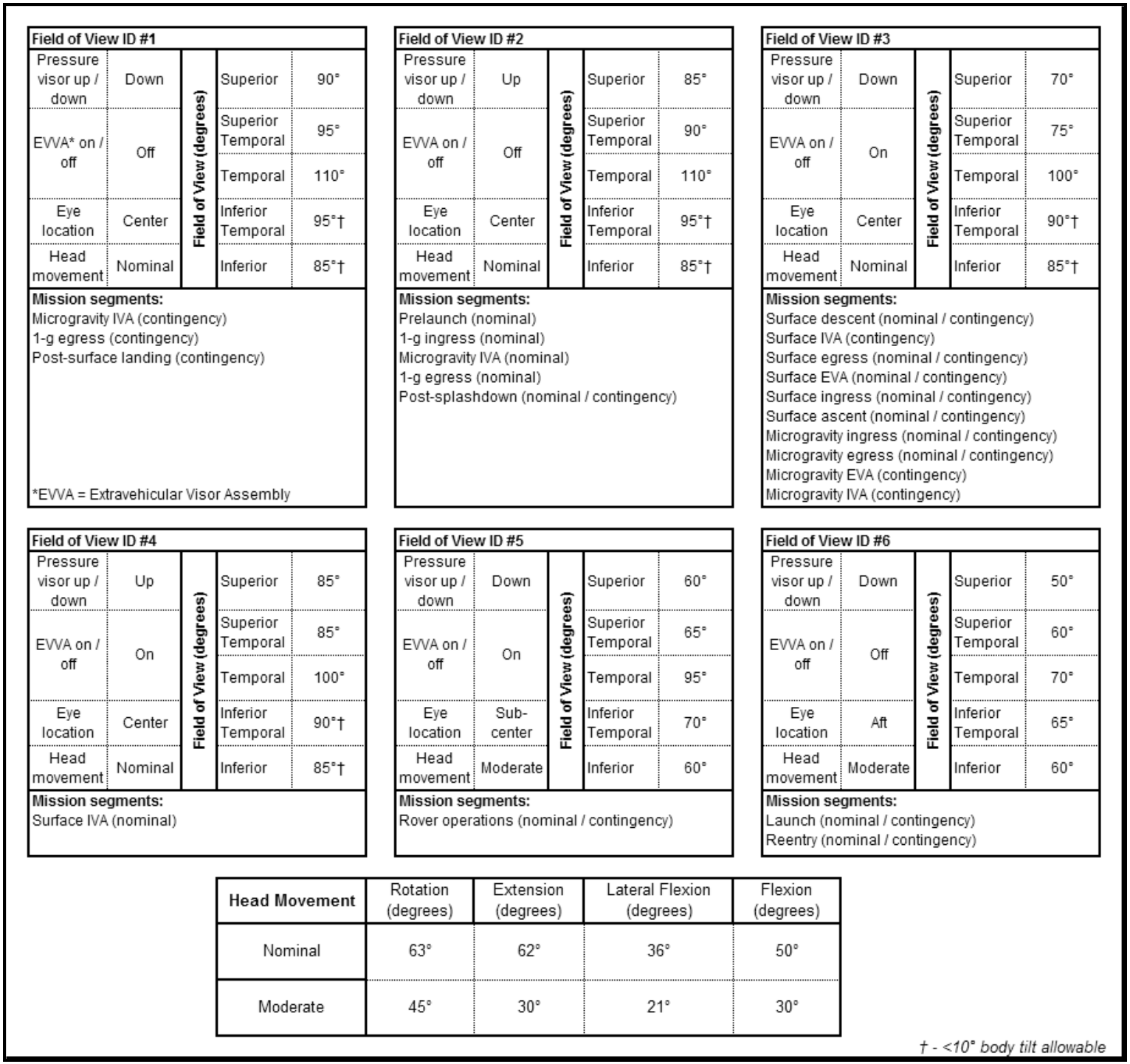

Table 1: Constellation Suit Field of View Requirement

\section{TEST SETUP AND METHODOLOGY}

\section{RECONFIGURABLE OPERATIONAL COCKPIT}

The dome of the Reconfigurable Operational Cockpit [ROC] was determined to be an ideal location to perform field of view tests. This dome, in Building 16 at NASA's Johnson Space Center [JSC] in Houston, TX, is designed to be used in conjunction with an Orion cockpit mockup. The ROC is a 24-foot diameter hemispherical dome with a series of 11 projectors capable of displaying one continuous image across the entire interior surface of the dome. An image of the ROC dome is shown below in Figure 3, and Figure 4 shows the interior projector bank which provides this continuous-image capability.
When used with the cockpit mockup, it provides a facility in which crewmembers and engineers can perform tests, evaluations, or training in a controlled cockpit environment, but also be able to view a modeled external environment through the windows, such as the hatch on the International Space Station during a docking maneuver.

However, with the cockpit mockup removed from the $\mathrm{ROC}$, the dome provides an empty platform with which to perform a field of vision test very similar to the Goldmann kinetic perimetry test, but with more flexibility and measuring range than typical visual field examinations. 


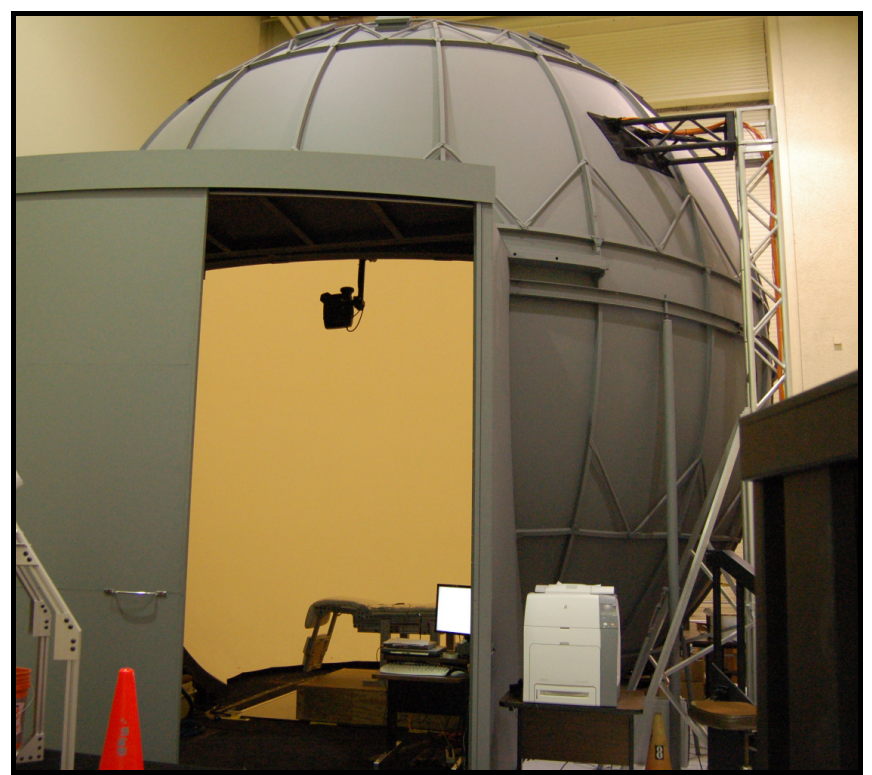

Figure 3: ROC Dome Exterior

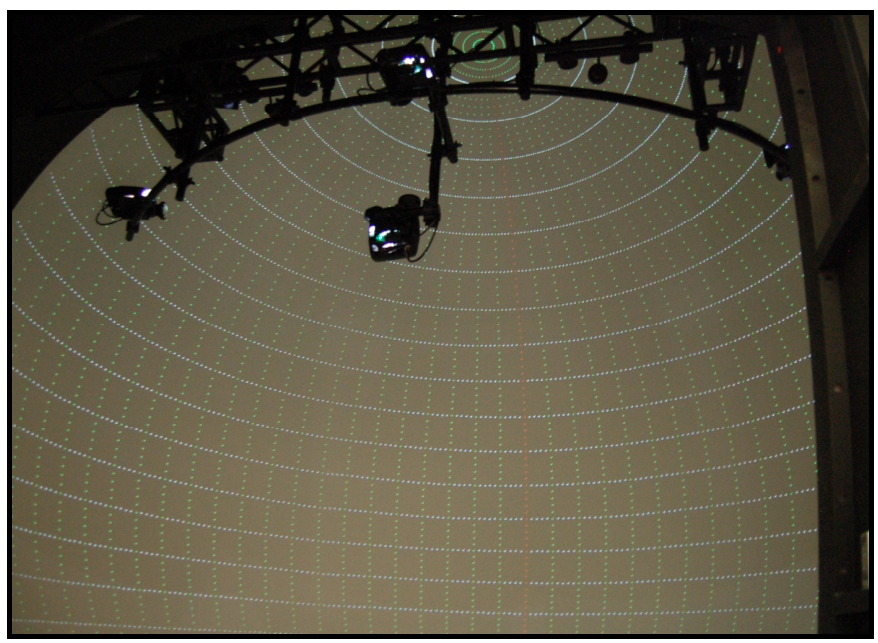

Figure 4: ROC Interior and Projector Bank

\section{TEST VARIABLES}

The following variables were considered important to evaluate for this field of view test:

- Multiple (2) subjects to allow for anthropometric variability and increased sample size

- Standing and recumbent body positions

- Various (4) helmet architectures

- Head fixed (no head motion) and body fixed (full head motion within the helmet) conditions

\begin{tabular}{|l|c|}
\hline Test Variable & Values \\
\hline Test Subject & 2 \\
\hline Body Position & 2 \\
\hline Suit/Helmet & 4 \\
\hline Head Rotation & 2 \\
\hline FOV Angles & 8 \\
\hline TEST POINTS & 256 \\
\hline
\end{tabular}

Table 2: FOV Test Matrix
Providing for the eight asymmetrical field of view angles, what results is a very large testing matrix as shown in Table 2. In addition, a sample size of at least three data points per test was implemented. This results in a minimum of 768 individually collected data points across the entire test series.

One of the most important variables that impact field of view is the suit and helmet architecture themselves. For this test, four helmets were chosen to represent an array of different possible helmet architectures:

\section{- Advanced Crew Escape Suit [ACES]}

- Current Shuttle Program suit; helmet shown below in Figure $5 \mathrm{~A}$.

- 1031 Pilot Protective Assembly [PPA]

- Conformal-type helmet with rotating neck bearing and face seal; similar 1030A helmet shown below in Figure 5B.

- Mark III Lunar Prototype

- Hemispherical "bubble-type" dome helmet which is analogous to current Constellation Lunar suit architecture; helmet shown below in Figure 5C.

- D-Suit with Neck Wedge

- Hemispherical "bubble-type" dome helmet with neck wedge; most analogous to current Constellation launch, entry and abort [LEA] suit architecture; helmet shown below in Figure 5D.

Although the ROC facility will be able to support pressurized suits in the future, this capability was not yet complete at the time of testing. Therefore, all tests were conducted unpressurized. It is highly desirable to test the pressurized condition for these suits in the future to quantify the difference between pressurized states; however, having only unpressurized data at this time does not make the test any less significant. In fact, suit pressure has almost no FOV impact on rigid suits like the Mark III (2) or conformal helmets like the PPA (7), and most suit architectures that are prone to FOV loss due to suit pressure have restraint mechanisms in place to adjust helmet positioning by the crewmember. For example, the ACES employs use of a pull-down strap to reposition the helmet on the head as necessary (8)

All suits were tested in their full configuration, with few exceptions. On the ACES, the ACES head retention assembly [HRA] was used instead of an entire suit. The HRA consists of a neck ring and counterbalance springs which replicate the pressure garment and helmet interface of the ACES. Due to the unpressurized nature of this test, it was determined to not have an impact on field of view; however in a pressurized test the full ACES suit will need to be utilized. On the D-Suit and Mark III, the helmet bubbles were not used as the tests were unpressurized and there was no alternative mechanism for providing breathing gas to the test subject. This is deemed to have negligible impact on FOV as these bubbles are clear and should not change the ability of the test subject to see in any direction. Lastly, although the 1031 is referred to as such throughout, the actual hardware tested was a 1031 suit with a 1034 helmet. The 1034 helmet is nearly geometrically equivalent to the 1031 with respect to field of view. 


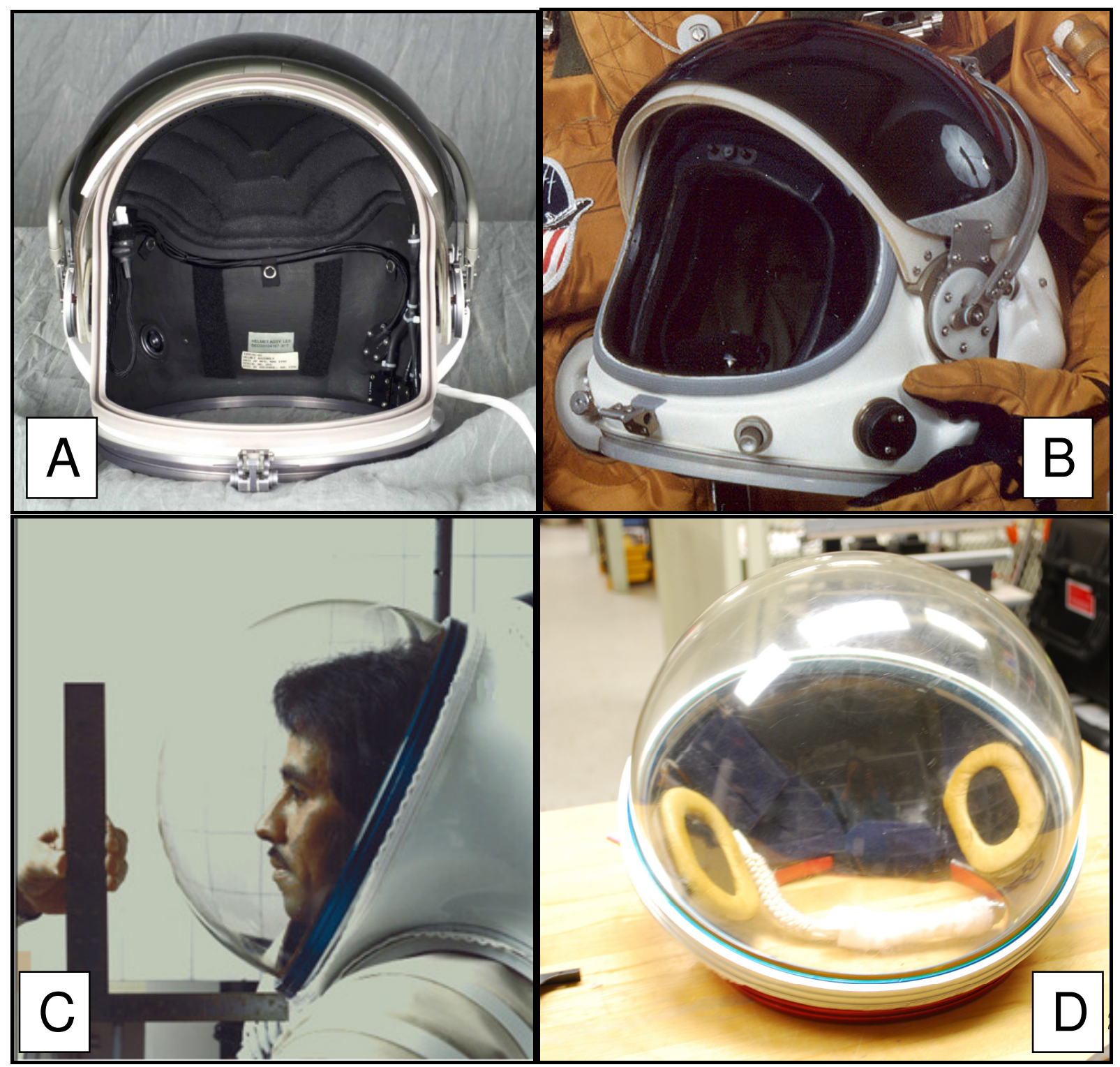

Figure 5: Four Helmets Selected for Field of View Testing

\section{TEST PARAMETERS AND CONTROLS}

As many test parameters as possible were borrowed from the Goldmann kinetic perimetry test, when feasible and applicable; remaining controls were based off need and engineering judgment. Regardless, it was necessary to fix and define as many potential confounding variables as possible.

For example, the marker that enters the test subject's field of view required strict definition. Borrowing from the Goldmann test, the marker speed was defined as 2 degrees per second incoming (4). Although there are various sizes of markers in the Goldmann test, we replicated the apparent size of the Goldmann Type II marker which results in a constant size of 12 arc-minutes as seen by the subject from the design eyepoint (4). The color of the marker was chosen as green, which is the human sensitivity peak of the light spectrum $(9$, the exact wavelength used was $510 \mathrm{~nm}$ ). The Goldmann test provides for varying of the marker brightness; although we did not have this capability, the projector (3D Perception model $\mathrm{SX}+40$ ) displayed a constant marker brightness of 3500 Lumen (10).

Other controls that were considered: minimum allowance for subject to adapt to darkened test conditions (1 minute); seat angle (0 degrees); subject height (compensated for); subject reaction time (not compensated for but estimated at 0.25 seconds, corresponding to 0.5 degrees at the constant marker velocity of 2 degrees per second).

There were some variables that were very difficult to control. Most notable was variability between the two test subjects. Although one male and one female were selected in hopes that a noticeable trend would emerge due to sizes in head anthropometry, this did not turn out to be the case due to differences in specific facial features and neck range of motion. Anthropometric data was collected on the two subjects, and is available in Appendix A. 
Due to the testing variables chosen and the limitations of the ROC facility, there were four unique test setups employed to gather all 768 data points for this test.

The first test setup consisted of a recumbent seat on a low platform. The subject, once suited, was placed into the seat (feet toward the screen) with the eyes positioned along a specific axis. The ocular height of the subject was recorded and the test software was updated to this new eyepoint. This test setup is shown in Figure 6.

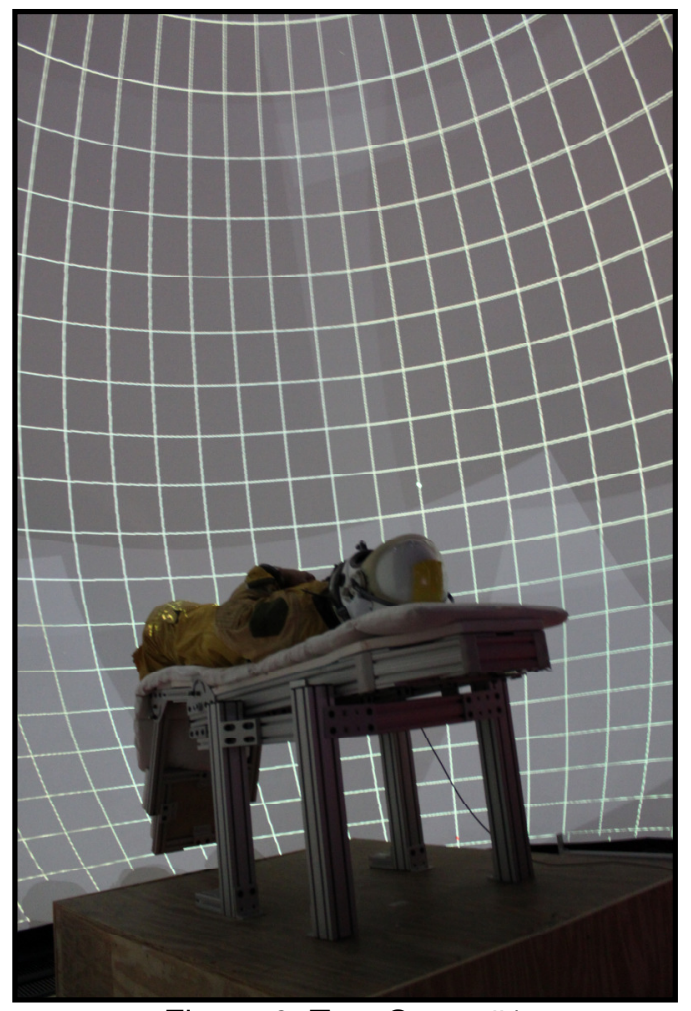

Figure 6: Test Setup \#1

The second test setup was similar to the first with the exception that the subject was rotated 180 degrees in the seat, with their feet facing away from the screen. This, in conjunction with the first test setup, allows for testing of all eight recumbent field of view directions, as the ROC dome was only roughly two-thirds of a sphere, thus not able to capture all field of view angles from one position. This test setup is shown in Figure 7.

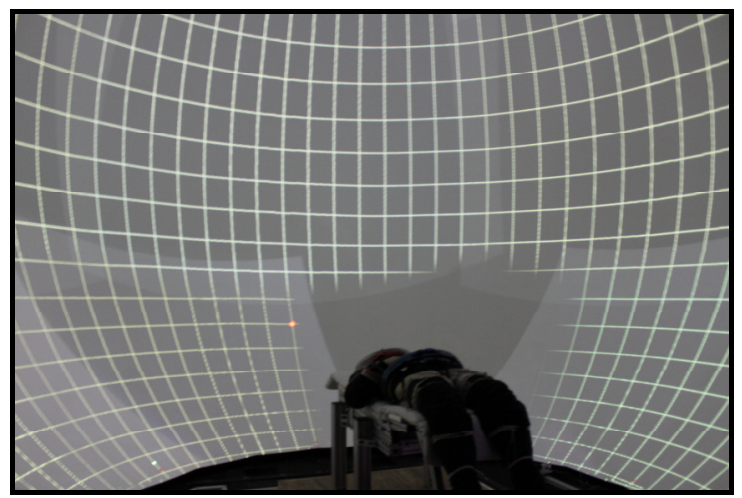

Figure 7: Test Setup \#2
The third test setup, shown in Figure 8, consisted of removing the seat and having the subject stand at the dome center. The ocular height was always measured and the software updated before each test run. The subject would occasionally be asked to rotate their body about the vertical axis to facilitate testing a specific direction, but the general test setup was the same.

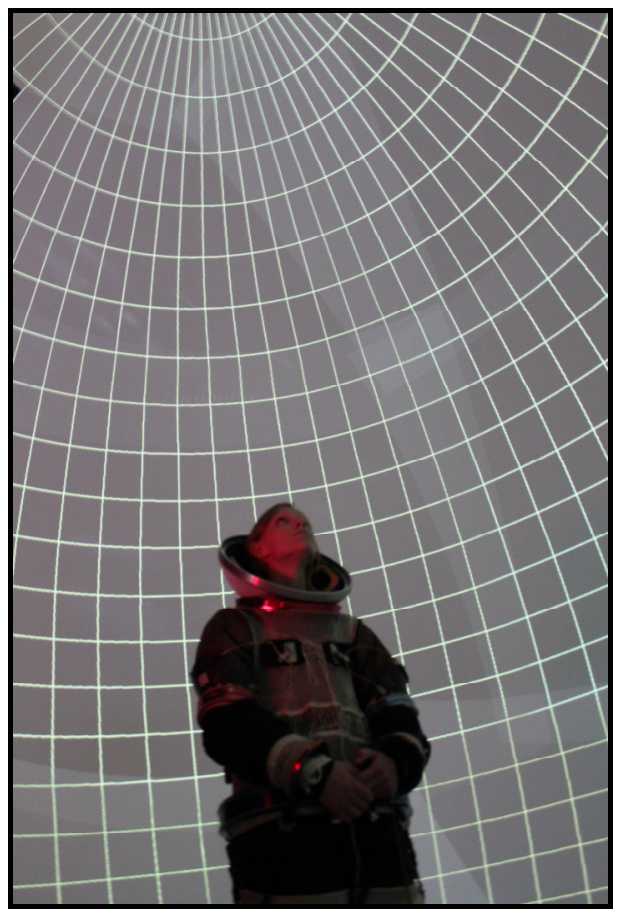

Figure 8: Test Setup \#3

A fourth test setup was necessary to capture some of the standing field of view angles in the downward direction (inferior; inferior temporal). This is the result of the geometry of the ROC dome and the lack of capability to measure angles near the feet when standing. To facilitate these measurements, a secondary testing device was constructed. This hardware consists of a small diffuse green light on a motorized track. The brightness and size of the green light was designed to match that of the projector, and the carriage is pulled along the track by a motor and pulley system. This test setup is shown in Figures 9, 10 and 11.

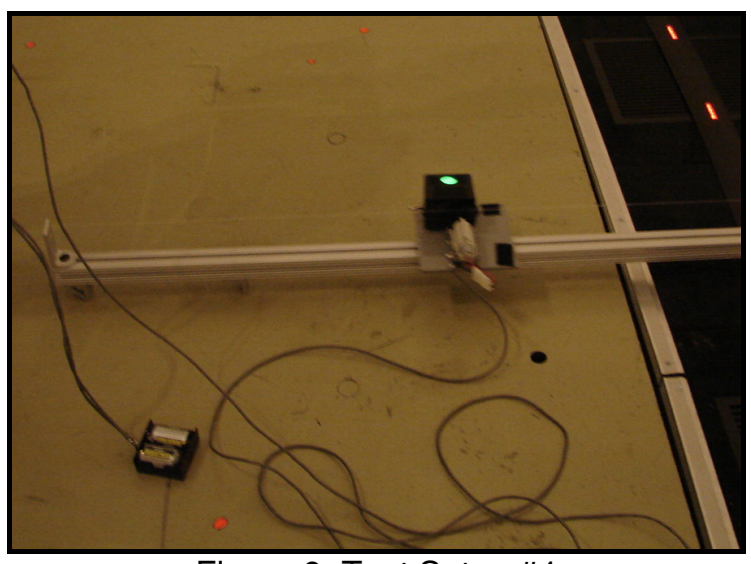

Figure 9: Test Setup \#4 


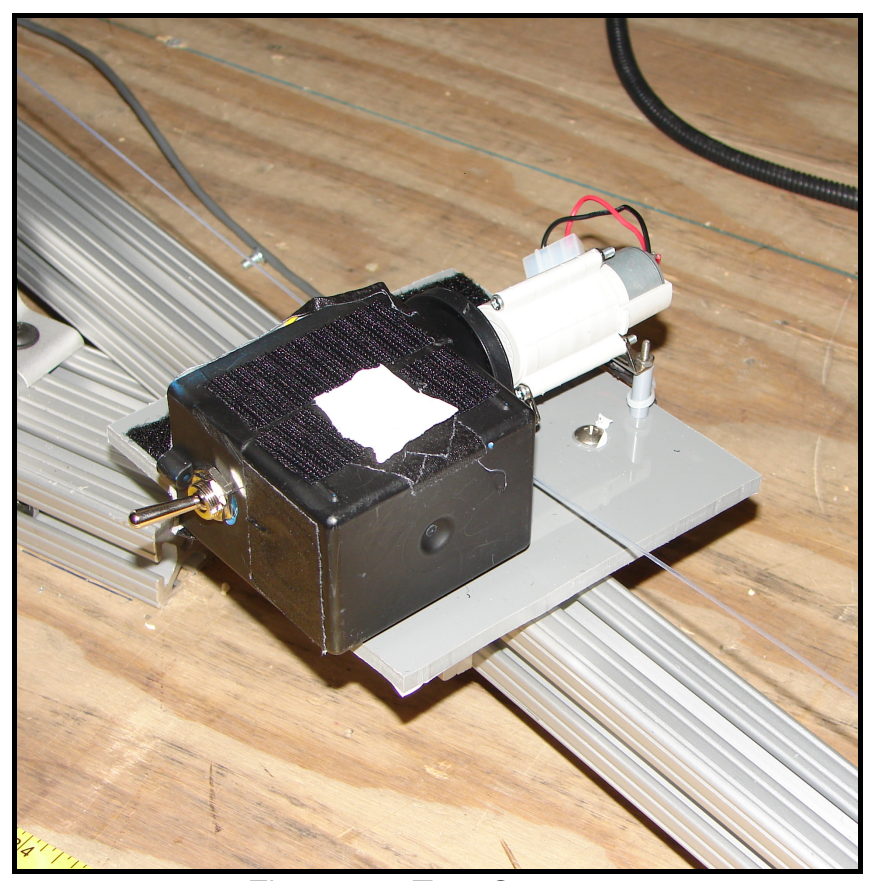

Figure 10: Test Setup \#4

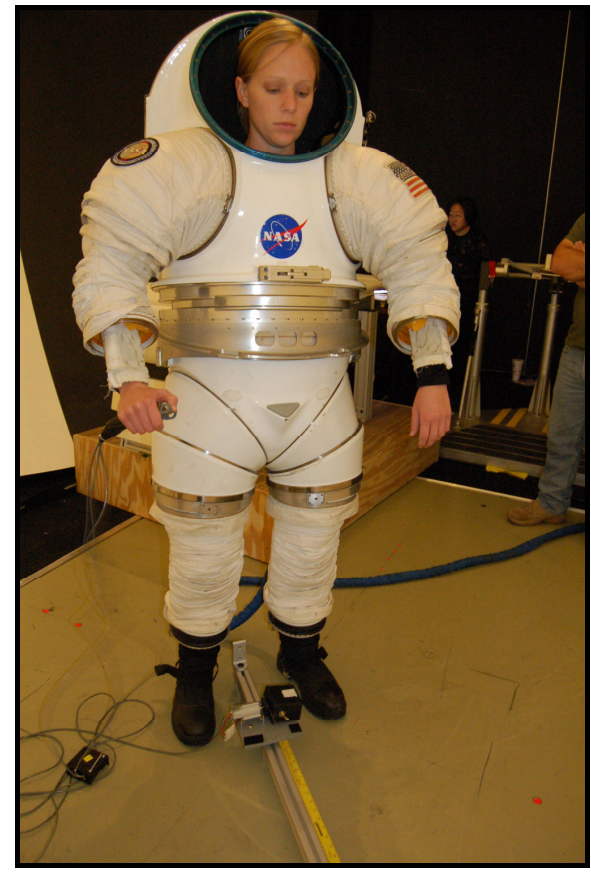

Figure 11: Test Setup \#4

The measuring range of each test setup and the specific test setup used for each field of view direction and body position is shown below in Table 3 .

\begin{tabular}{|l|c|c|c|c|}
\hline $\begin{array}{l}\text { Measuring range and } \\
\text { test setup used for each } \\
\text { field of view direction }\end{array}$ & $\begin{array}{c}|c| \\
\text { Measuring } \\
\text { Range }\end{array}$ & $\begin{array}{c}\text { Test } \\
\text { Setup \# }\end{array}$ & $\begin{array}{c}\text { Measuring } \\
\text { Range }\end{array}$ & $\begin{array}{c}\text { Test } \\
\text { Setup \# }\end{array}$ \\
\hline Superior & $120^{\circ}$ & 2 & $180^{\circ}$ & 3 \\
\hline Superior Temporal & $120^{\circ}$ & 2 & $180^{\circ}$ & 3 \\
\hline Temporal & $\pm 120^{\circ} / \pm 160^{\circ}$ & $1^{*} / 4$ & $\pm 240^{\circ}$ & 3 \\
\hline Inferior Temporal & $120^{\circ}$ & 1 & $120^{\circ}$ & 4 \\
\hline Inferior & $120^{\circ}$ & 1 & $120^{\circ}$ & 4 \\
\hline
\end{tabular}

Table 3: Test Setup Measuring Ranges
For the first three test setups, which utilized the projectors, the subject was given a button to push when the object entered their field of view. The measurement was recorded automatically by the computer. For the fourth test setup using the external light track, the subject was given a 2-way spring-loaded thumb switch. The switch was depressed to make the light move into the field of view, and let go when it was seen. This data was recorded manually by the test conductor. These two switches are shown in Figures 12 and 13. There did not seem to be a difference in reaction time or accuracy between these two switches.

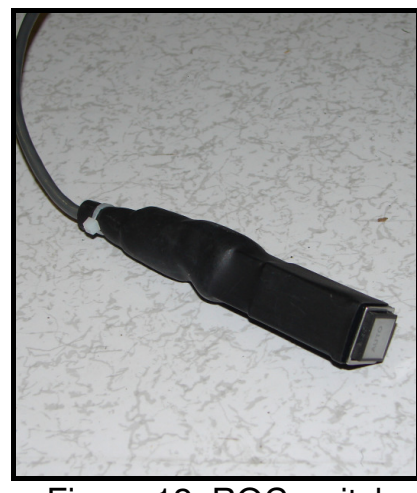

Figure 12: ROC switch

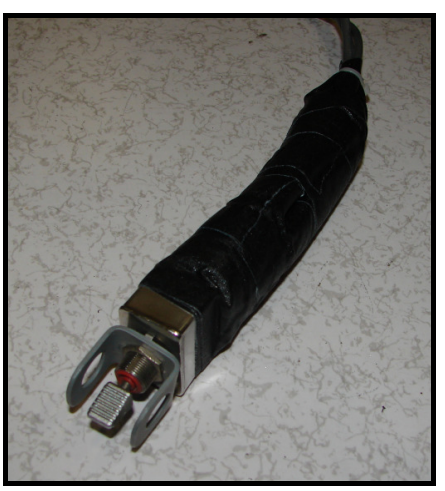

Figure 13: Track switch
For all tests, the subject was told from which direction the marker would enter their field of view; i.e., the subject did not need to scan around the periphery to locate the marker. In addition, for all head-fixed tests, the subject was given a large red marker at the center of their field of view with which to focus and fix their head prior to each data point. For the body-fixed tests, where all head motion (but no shoulder motion) was allowed, the subject was instructed to rotate their head and look in the specified direction prior to beginning each test run.

The software used to project the grid/marker and collect and record the data was written in $\mathrm{C}$.

\section{RESULTS AND ANALYSIS}

Raw collected data is shown below in Tables 4 and 5 . These tables provide all of the 256 test points, each an average of at least three collected data points. In these tables, abbreviations are used as follows: $\mathrm{M}=$ male; $\mathrm{F}=$ female; $\mathrm{HF}=$ head fixed; $\mathrm{BF}=$ body fixed (head can rotate). All angles are in degrees from the central visual line.

This data does not assume left-to-right symmetry of the temporal angles. Although theoretically symmetry should occur in most helmets, it often does not due to variability in suit or helmet fit, facial geometry, head placement during a test, or asymmetrical head rotation. Therefore, symmetrical data was not provided in the body of this paper to try to reflect "real-world" conditions of suit/human fit. However, this data corrected for perfect symmetry (i.e., left-to-right angles are averaged) is available in Appendix B. 


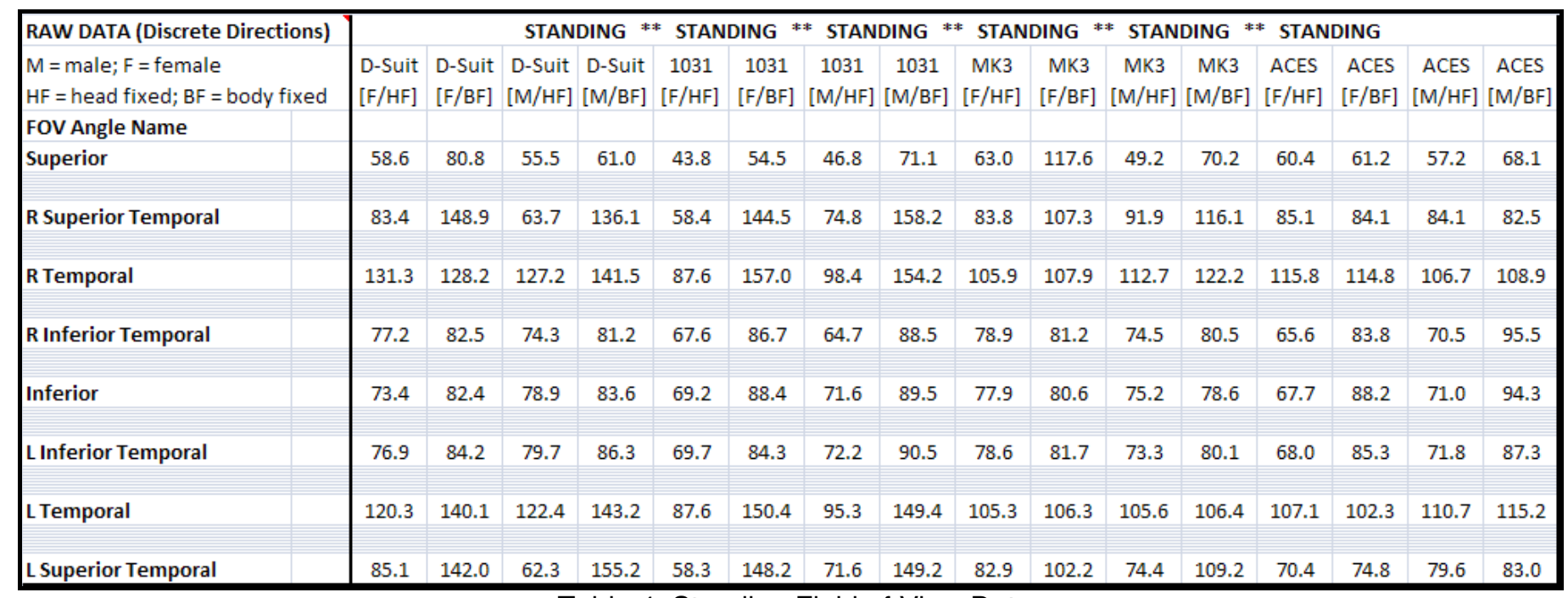

Table 4: Standing Field of View Data

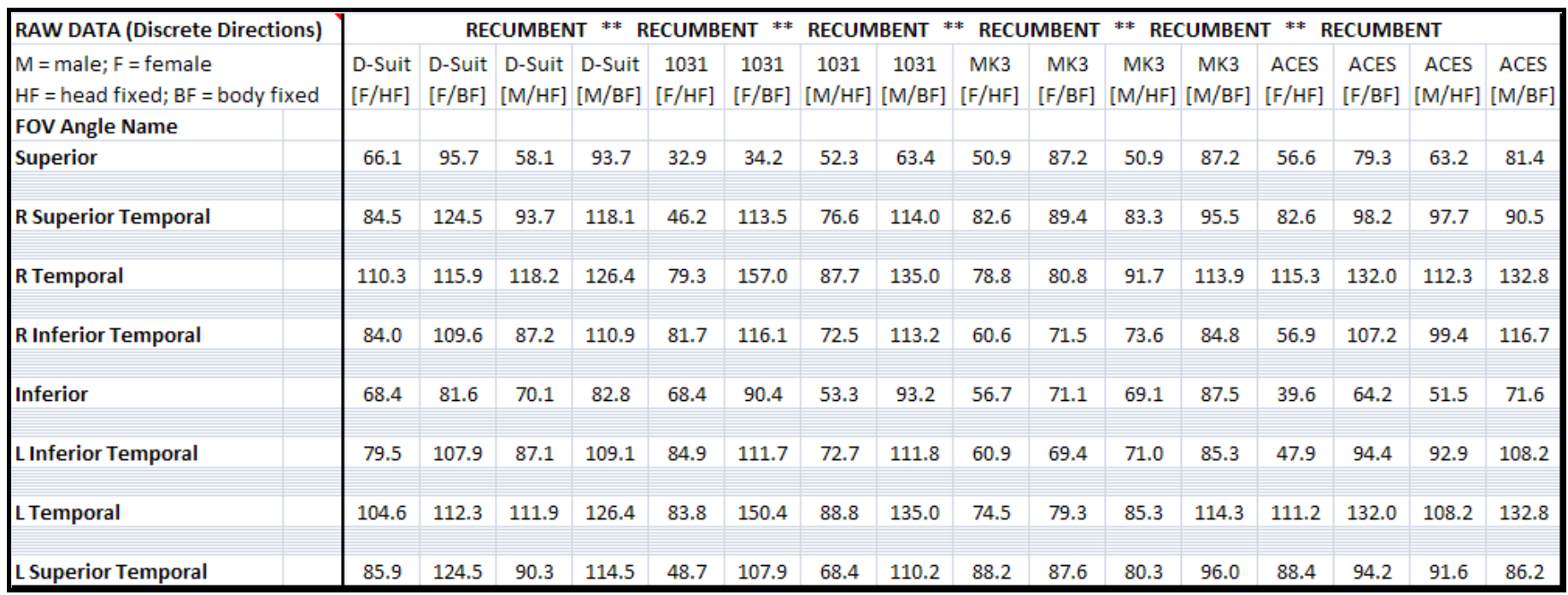

Table 5: Recumbent Field of View Data

\section{CONTROLLING FOR SEX AND BODY POSITION}

With so many test variables to evaluate, there are numerous ways to graph and present this data. For example, choosing a specific subject and body position, one can compare the four different suits to gauge the difference in viewability for each field of view angle. Shown at right in Figure 14 is the female subject, standing with no head movement.

As shown, while the downward angles cluster within about 10 degrees with little variability, the temporal and upward angles show the Mark III and D-Suit performing very well while the 1031-PPA helmet fairs very poorly. This is no doubt due to the conformal nature of the 1031, which uses a face seal and limits upward and sideward viewing (one will note that 1034 and 1031 are used interchangeably throughout - although a 1031 suit was worn during testing, the helmet tested was the 1034, nearly equivalent with respect to FOV).

Contrast this chart with Figure 15. This chart shows the same test, but now the test subject is instructed to move their head.

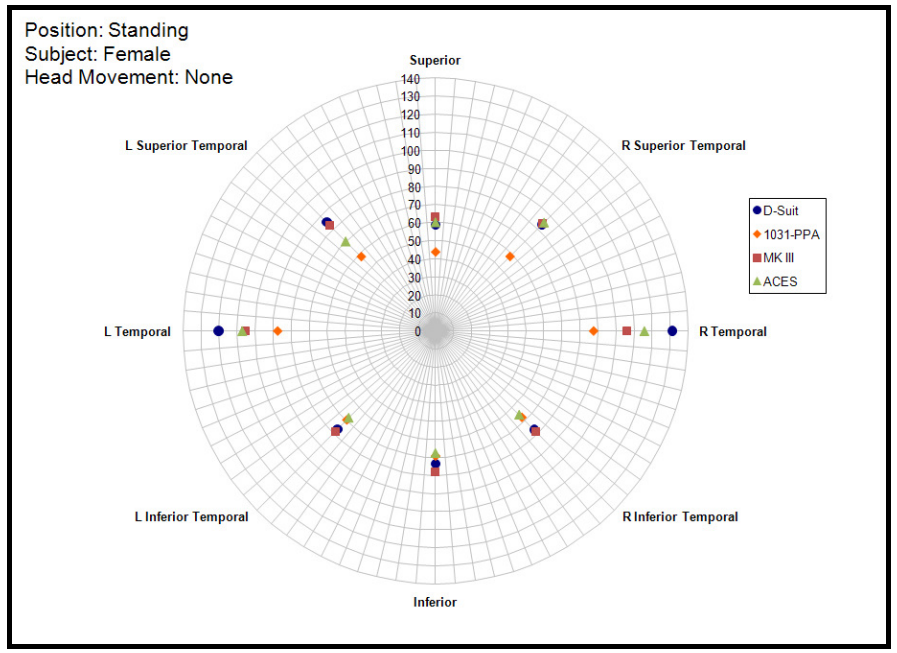

Figure 14: Standing Head-Fixed Female FOV 


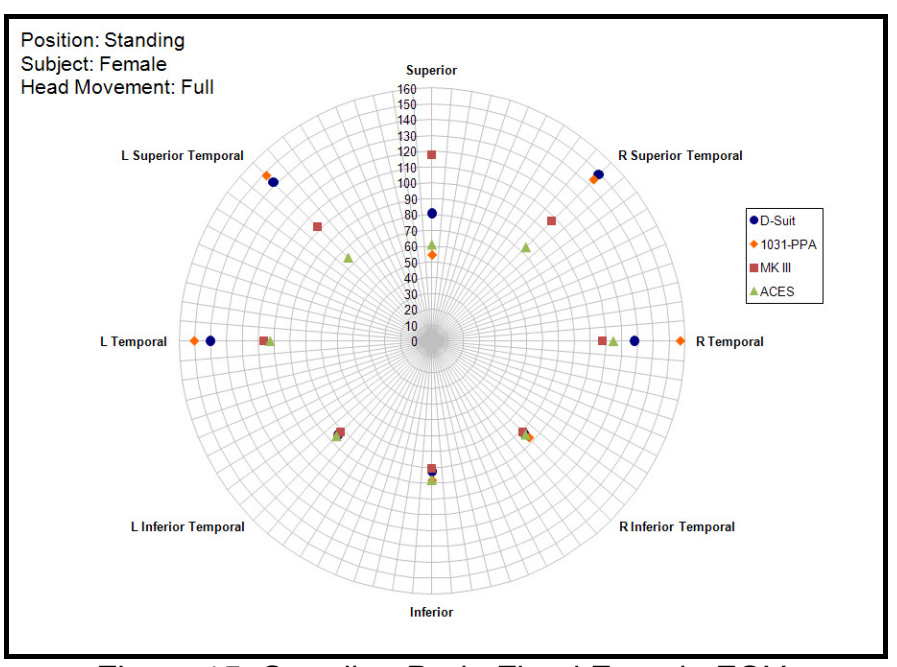

Figure 15: Standing Body-Fixed Female FOV

The difference is remarkable. Although the same clustering occurs for the downward angle, the neck bearing of the 1031 allows for a drastic increase in vision through head rotation. The other helmets, which do not have a neck bearing (or in the case of the ACES, have a neck bearing but head rotation occurs independent of the helmet and does not force rotation of the bearing), only see a moderate increase (or none at all) through head rotation. However, one will notice that the upward viewing of the 1031 does not see the same improvement, as the neck bearing does not aid in that direction (It should be noted that while the ACES neck bearing does not rotate when the head is rotated, the subjects, if allowed to use their hands to rotate the neck bearing, would be able to see more than 180 degrees left and right) (1).

A table similar to Tables 4 and 5 , which shows the delta for each test point between a head-fixed state and a body-fixed state, is available in Appendix C. By viewing the data in this manner, a few trends emerge:

- There is no difference in how much head movement improves field of view between standing (23.2 degrees average) and recumbent (24.3 degrees average) for all directions/suits, although there was some variability between suits

- There is no difference between the male and female test subject's ability to improve field of view through head motion (23.5 degrees average and 24.1 degrees average, respectively)

- The Mark III and ACES were least sensitive to head rotation (14.1 and 13.9 degrees average increase across all field of view directions)

- The D-Suit was marginally better at 23.8 degrees average improvement across all directions

- The 1031 suit, which consists of a conformal helmet with neck bearing, provides a very large field of view increase through head movement (43.3 degrees average across all directions)
Now compare Figure 15 to the data shown below in Figure 16. Where Figure 15 was a standing body-fixed test, Figure 16 shows a recumbent body-fixed field of view.

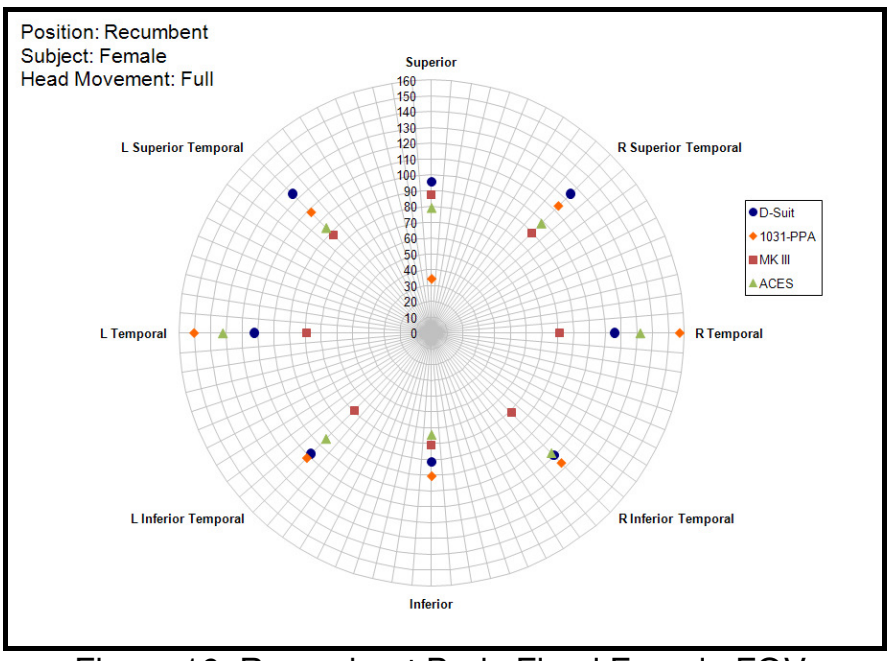

Figure 16: Recumbent Body-Fixed Female FOV

It is generally assumed that a recumbent field of view is worse than a standing field of view, due to the gravity vector and the subject's head being further back inside the helmet shell. This chart, when compared to the chart in Figure 14, holds this to be true; however there are some noticeable differences. The conformal 1031 has a very small loss, while the Mark III, D-Suit, and to a lesser extent, the ACES, see a much larger loss.

All graphs, showing each gender/body position/head rotation variable (a total of eight of them) are available in Appendix D.

\section{CONTROLLING FOR SUIT}

Also of interest is to see every collected test point for a specific suit on one graph. Doing so allows visualization of the difference between the two subjects; between body positions, and between head movements. Such a graph is shown in Figure 17.

By comparing different points on the graph at the same viewing angle, it is easy to see how the field of view of a suit/helmet changes as a function of body position and head motion. It also demonstrates the variability due to subject head size and anthropometry.

As shown in Figure 17, the 1031-PPA helmet is very sensitive to changes in the subject, the ability or inability to move one's head, and (to a lesser extent) body position. Contrast this with Figure 18, which shows the Mark IIII Lunar Prototype suit. 


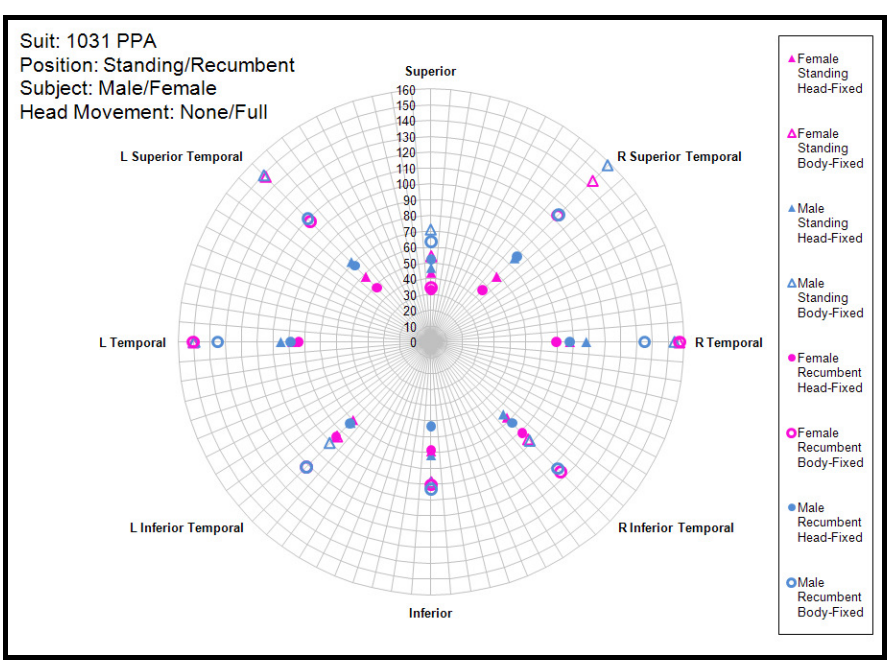

Figure 17: 1031-PPA (All Data)

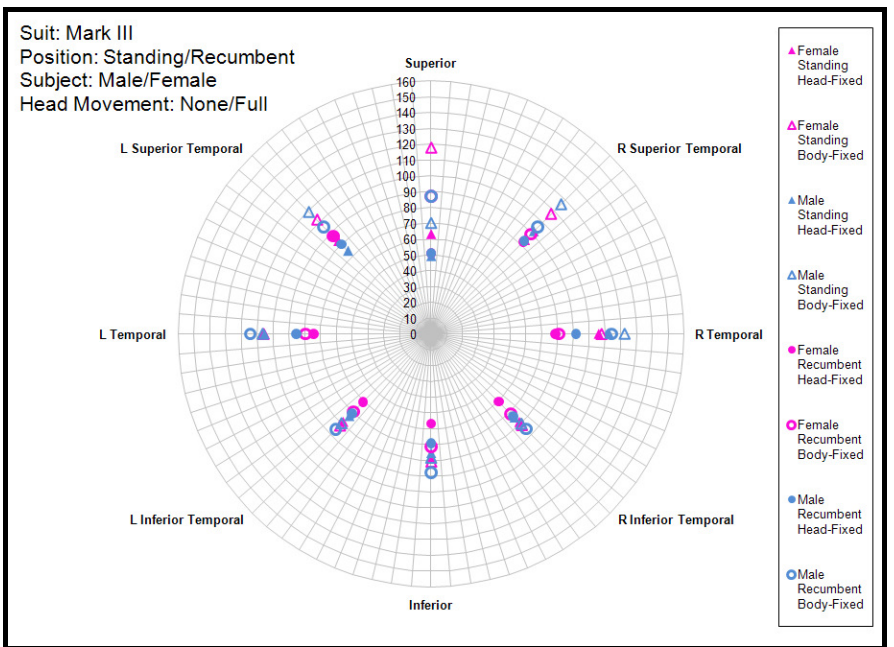

Figure 18: Mark III (All Data)

The Mark III demonstrates a much lower sensitivity to changes in anthropometry and head motion as demonstrated by the relative clustering of the data points in each field of view direction.

The field of view data for the two remaining suits, the ACES and the D-Suit, are shown above in Figures 19 and 20 , respectively.

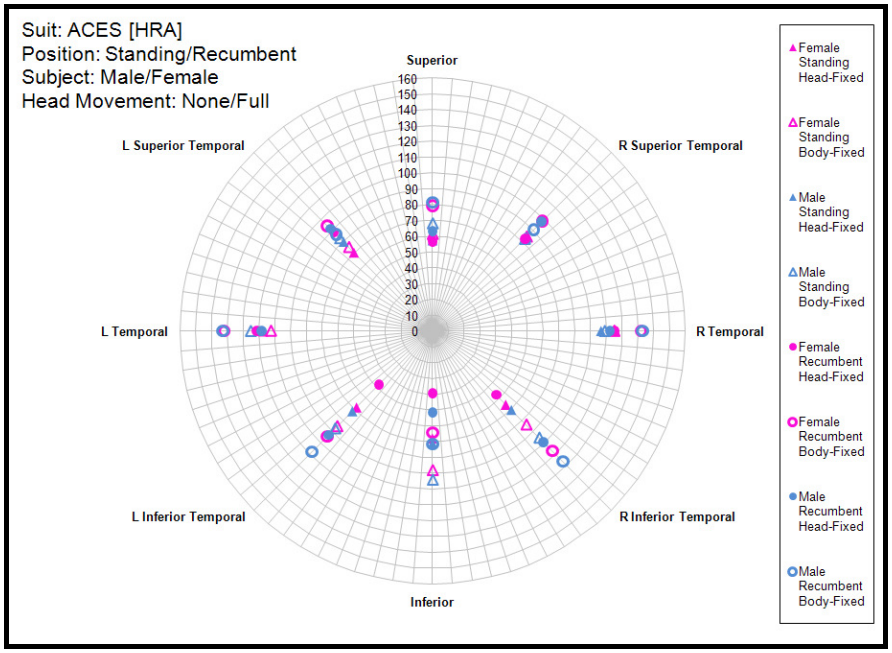

Figure 19: ACES (All Data)

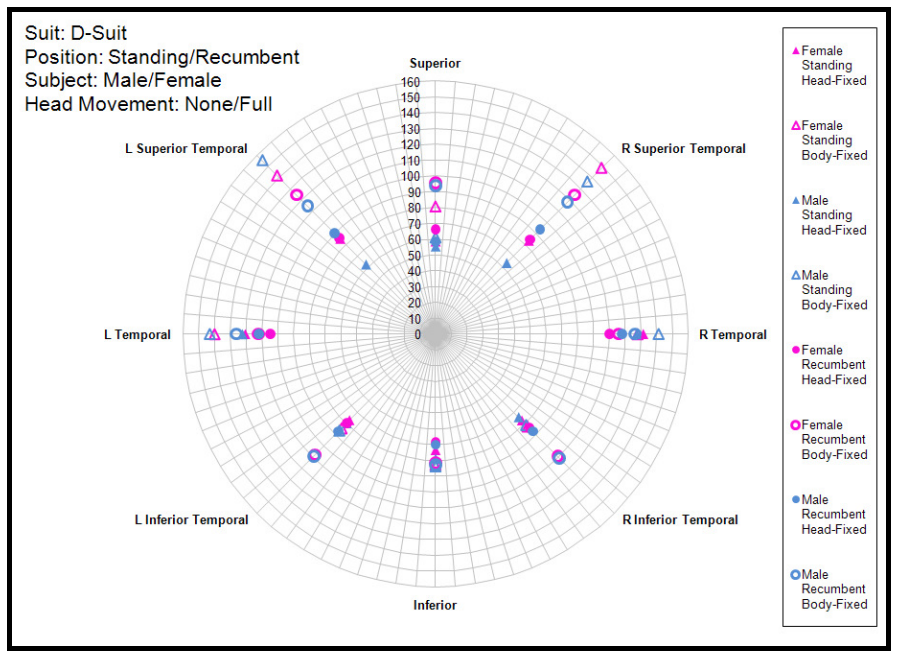

Figure 20: D-Suit (All Data)

\section{CONTROLLING FOR FIELD OF VIEW DIRECTION}

Another way of looking at this same data is to look at one direction at a time. By doing this, it is much easier to see how changes in body position or head rotation have an effect on the apparent field of view of the crewmember. For example, in Figure 21 below, the same data is displayed in the Inferior Temporal viewing angle only.

One can easily see the difference between adjacent suits, or the vision increase observed when switching from a head-fixed test to a test where head rotation is allowed. The graphs for the other field of view directions are available in Appendix E. 


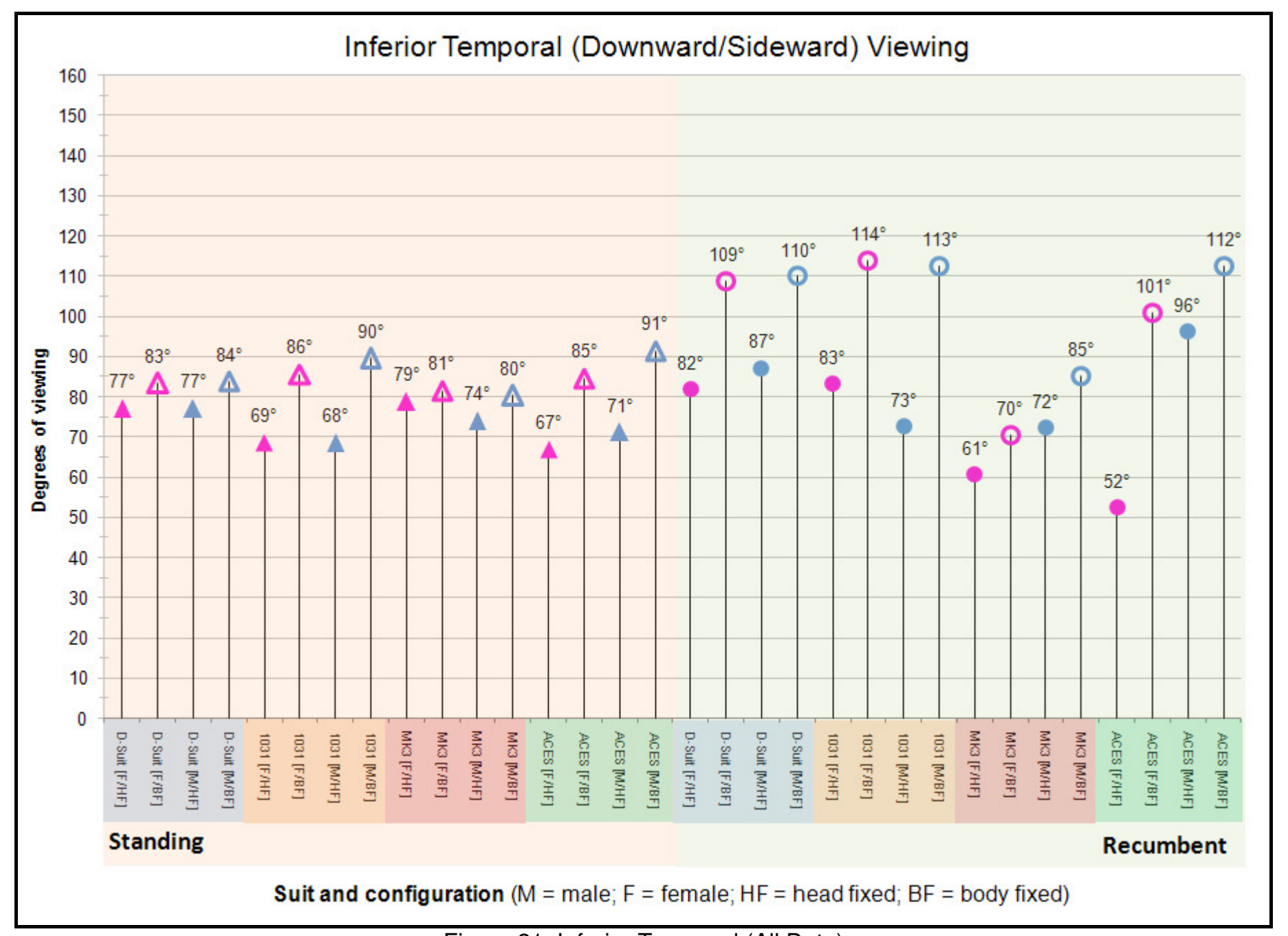

Figure 21: Inferior Temporal (All Data)

\section{TEST SUBJECT VARIABILITY}

An analysis was performed to quantify the delta between the female test subject and the male test subject. Prior to the test, an effort was made to choose two subjects of different sizes in order to quantify the difference in field of view between different size heads, and interpolate the results to the anthropometric extremities of a $99^{\text {th }}$ percentile male and $1^{\text {st }}$ percentile female. For example, the symmetrical delta on the D-Suit is shown in Table 6.

One can notice that surprisingly, there was no average difference $(n=32 ; S D=8.53)$ between the two subjects for this suit, despite there being very large differences for some distinct test points. There was a small $(+2.7)$ degree delta for the recumbent points but an equal and opposite (-2.7) degree delta for the standing case.

However, there is information to be gained from this analysis. Despite the male subject having a larger head (See Appendix A for exact anthropometry), it was noticed during the test that the male had a much more prominent brow than the female subject. As such, superior angles suffered when using a suit where the facial geometry itself limited upward viewing, such as the D-Suit. The Mark III, which has similar relevant geometry, did show a similar trend.

\begin{tabular}{|l|c|c|c|c|}
\hline Female to Male Delta & \multicolumn{5}{|c|}{ D-Suit } \\
\hline Body Position & \multicolumn{2}{|c|}{ Standing } & \multicolumn{2}{|c|}{ Recumbent } \\
\hline Head Motion & HF & BF & HF & BF \\
\hline Superior & -3.2 & -19.8 & -8.0 & -2.0 \\
\hline R Superior Temporal & -21.3 & +.2 & +6.8 & -8.2 \\
\hline R Temporal & -1.0 & +8.2 & +7.6 & +12.3 \\
\hline R Inferior Temporal & -.0 & +.4 & +5.4 & +1.2 \\
\hline Inferior & +5.5 & +1.2 & +1.7 & +1.2 \\
\hline L Inferior Temporal & -.0 & +.4 & +5.4 & +1.2 \\
\hline L Temporal & -1.0 & +8.2 & +7.6 & +12.3 \\
\hline L Superior Temporal & -21.3 & +.2 & +6.8 & -8.2 \\
\hline Individual Average & -5.3 & -.1 & +4.2 & +1.2 \\
\hline Suit/Position Average & \multicolumn{5}{|c|}{+2.7} \\
\hline Suit Average & \multicolumn{5}{|c|}{+.0} \\
\hline
\end{tabular}

Table 6: D-Suit Female/Male Delta

The data for the other three suits are available in Appendix F, but there were several apparent trends from the data:

- D-Suit and MK3 showed a field of view loss for the male subject, likely due to facial geometry 
- The MK3, 1031 and ACES showed an average field of view gain (all directions) of 3.9, 4.1 and 5.9 degrees respectively $(n=32 ; S D=14.2,11.7,11.2)$; however, all suits had mixed results of positive and negative deltas

- In the ACES and 1031, where the suit limits superior field of view (and not facial geometry) the male subject saw an average of 12 degrees more in the superior direction

- Ignoring the superior and superior temporal angles, the male subject on average viewed 4.7 degrees more than the female subject across all suits $(n=5 ; S D=0.8)$

- The delta was typically larger for the non-conformal suits in the recumbent position, where gravity placed the head further back against the helmet shell

- In the 1031, the male subject viewing was considerably larger than the female in the superior and superior temporal directions (Average of 13.8 degrees; $S D=9.7$ )

- In the 1031 , it is possible to calculate the amount of head rotation of each subject by comparing the headfixed to body-fixed data. While the female averaged 69.1 degrees of head rotation $(n=4 ; S D=6.3)$, the male only averaged 50.9 degrees $(n=4 ; S D=4.8)$.

- Across all test points, the average delta between the female and male subjects was 3.5 degrees $(n=128$; $\mathrm{SD}=11.7$ )

This analysis shows that while there is a rough correlation between head size and field of view, variabilities of the suit architecture, helmet geometry and specific facial geometrical features may actually result in a negative correlation in some viewing directions.

\section{STANDARD DEVIATION AND ERROR}

In order to ensure statistically relevant data, the standard deviation of all collected data points was calculated and analyzed against the test variables (sex, body position, suit, etc.) The full results are available in Appendix G and relevant statistics are as follows:

- The average standard deviation for all test points was 1.7 degrees (standard deviation of the minimum 3 data points whose average make up each test point)

- There was negligible difference between the average female standard deviation of 1.74 degrees, and the male, 1.63 degrees

- The 1031 had the lowest standard deviation of all suits at 1.43, while the ACES had the highest at 1.97

- There was negligible difference between the standard deviation of all head-fixed measurements (1.63) and body-fixed measurements (1.74)

- The standing measurements taken by the ROC dome had an average standard deviation of 2.25 , while the recumbent measurements had an average of 1.75

- The track light hardware, which was used to measure all standing inferior and inferior temporal angles, had an average standard deviation of only 0.59
This last point, the disparity in measurement consistency between the ROC and the track light, was possibly due to the method employed to move the marker. In the ROC test setup, the marker started outside of the subject's field of view and an apparently random amount of time (3-30 seconds) would pass before it entered the field of view. In contrast, the track light was started and stopped by the subject. The wait time for these track light data points, on average, was substantially less than the ROC dome data points. As such, the subject may have been momentarily distracted more often in the ROC tests. Future work has been identified to reduce the average wait time of these ROC test runs by starting the marker from a more optimal position closer to the subject's field of view.

\section{CONSTELLATION PROGRAM}

A Goldman Perimeter graph of the Constellation requirement for field of view is shown in Figure 22.

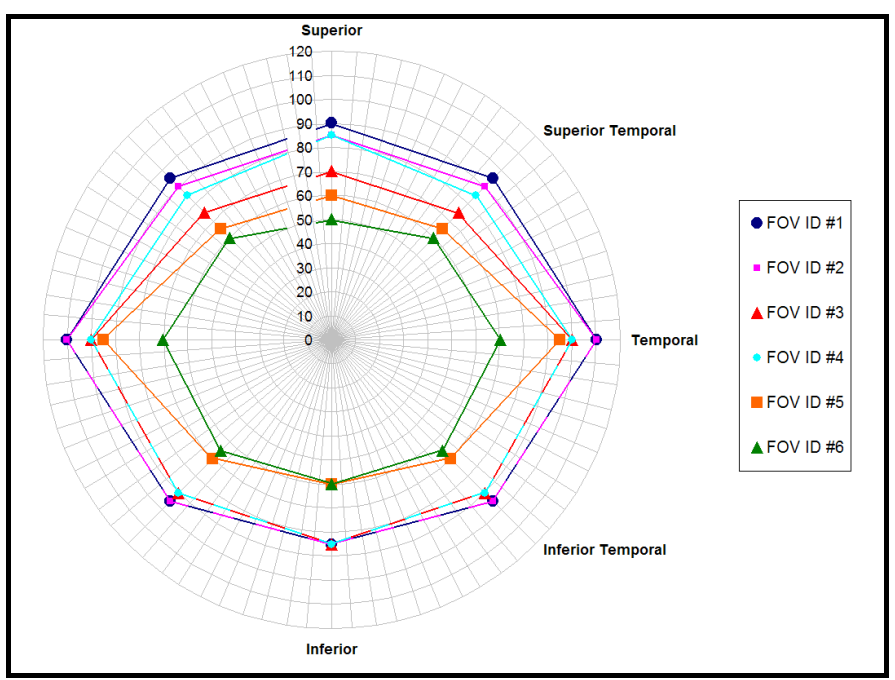

Figure 22: Graph of Constellation FOV Requirement

As shown previously in Table 1, the Constellation Program has a set of field of view requirements that are more expansive than previous NASA programs (11). Naturally it is of interest to compare the field of view performance of current and previous suits to the new Constellation Program requirement.

For example, FOV ID \#6 (shown in green above in Figure 22) corresponds to the field of view requirement for the launch, entry and abort phase of a mission. The ACES and 1031 are designed for these types of environments. As such it makes sense to compare the field of view performance of these suits to this requirement. Such a comparison is shown below in Figures 23 and 24.

In these figures, the orange polygon represents the LEA requirement for field of view, and the green polygon represents the requirement during an emergency egress. Typically due to operation concepts, this emergency egress requirement would become the driving case for an LEA helmet as a crewmember may transition from an LEA scenario to an egress scenario with little or no notice. This may preclude the crew from reconfiguring the helmet from an LEA mode to an emergency egress 
mode, thus making the more expansive emergency egress FOV requirement the driving case. However, depending on suit architecture and implementation a discrete LEA mode may be possible and therefore, is tracked differently in the Constellation requirement (11).

As can be seen in Figure 23, the ACES essentially meets the Constellation requirement in temporal viewing for all test cases; however, it only meets a few of the superior angles from the emergency egress requirement, and performs quite poor as compared to the requirement in the inferior directions. It should be restated that the ACES suit was designed to its own set of requirements which it met at the time (12); Figure 23 shows the ACES against the new requirement for Constellation, which is considerably more expansive in many instances.

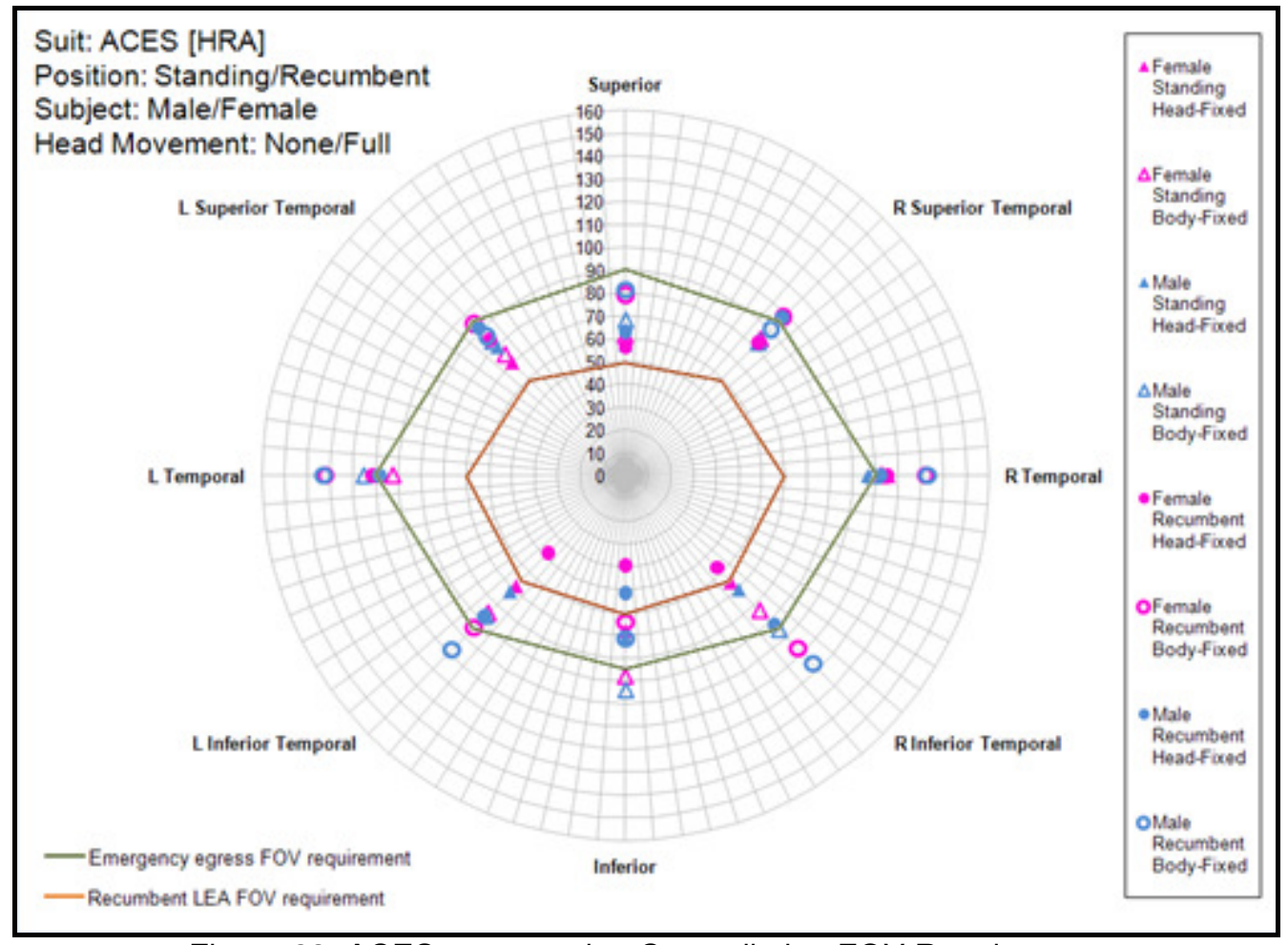

Figure 23: ACES compared to Constellation FOV Requirement

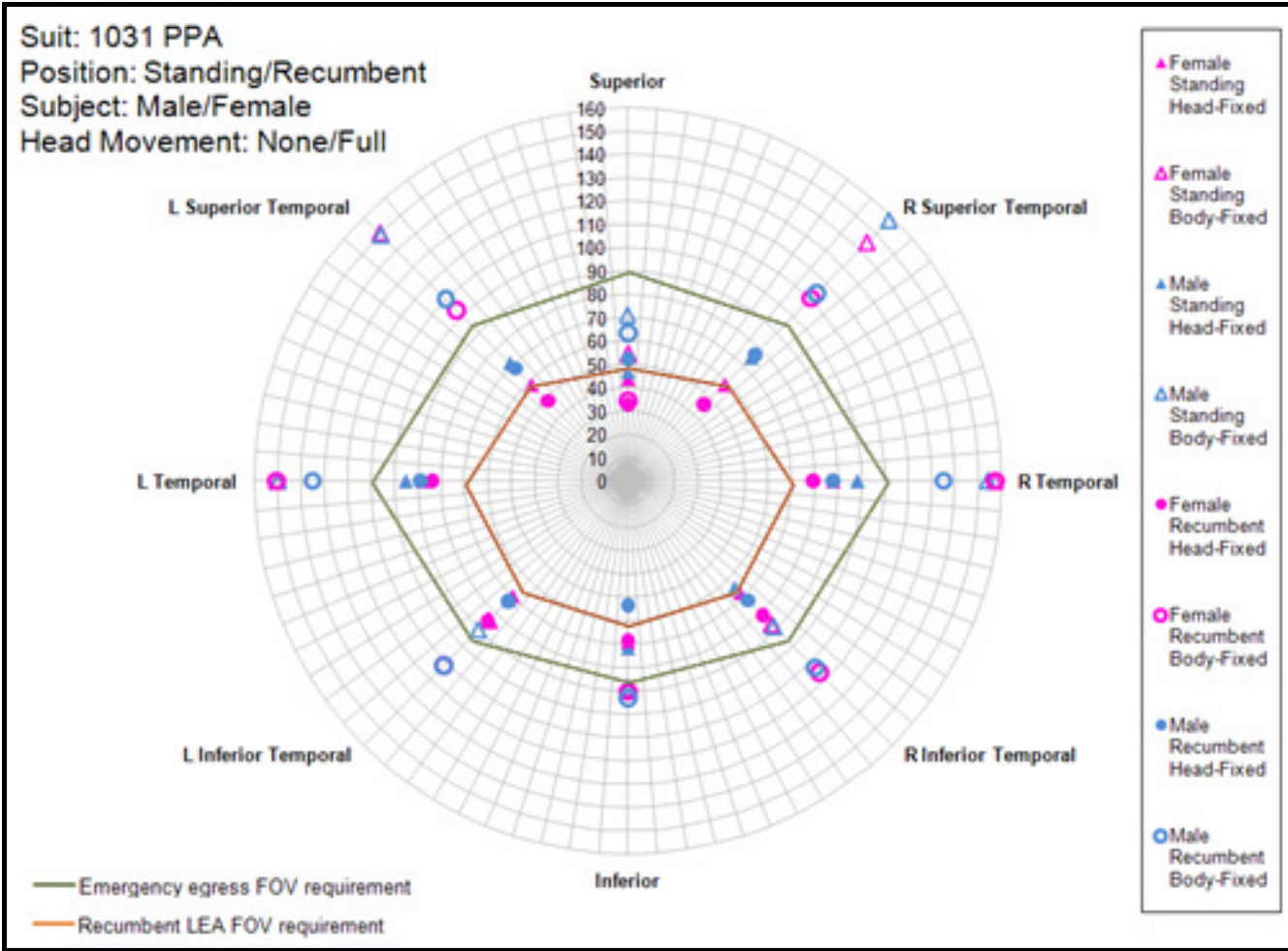

Figure 24: 1031-PPA compared to Constellation FOV Requirement 
Figure 24 shows that the 1031 does a worse job at meeting the requirement than the ACES when the head is fixed; however, when head rotation is allowed it meets the Constellation requirement in essentially every direction and test case except the superior direction. Note that per Table 1, the Constellation requirement allows up to 63 degrees of head rotation to facilitate meeting this requirement. Therefore, the 1031 is actually closer to meeting the Constellation requirement than the ACES helmet is when this head rotation is considered.

Similarly, we can compare the other suits to its relevant requirement. For example, Figure 25 shows the Mark III Lunar Prototype suit against the Constellation Program requirement for Surface EVA field of view. While the superior angles are met, and the temporal angles are within reach, the inferior viewing from the Mark III is substantially less than the requirement, even when providing for head rotation. Significant improvements must be made to a suit with similar architecture to facilitate meeting the requirement for inferior field of view. The Mark III was not designed with a specific field of view requirement as a driver, so it should be noted that the Constellation Configuration 2 suit (designed for the Lunar surface and with similar architecture to the Mark III) should be able to vastly improve the field of view above the Mark III.

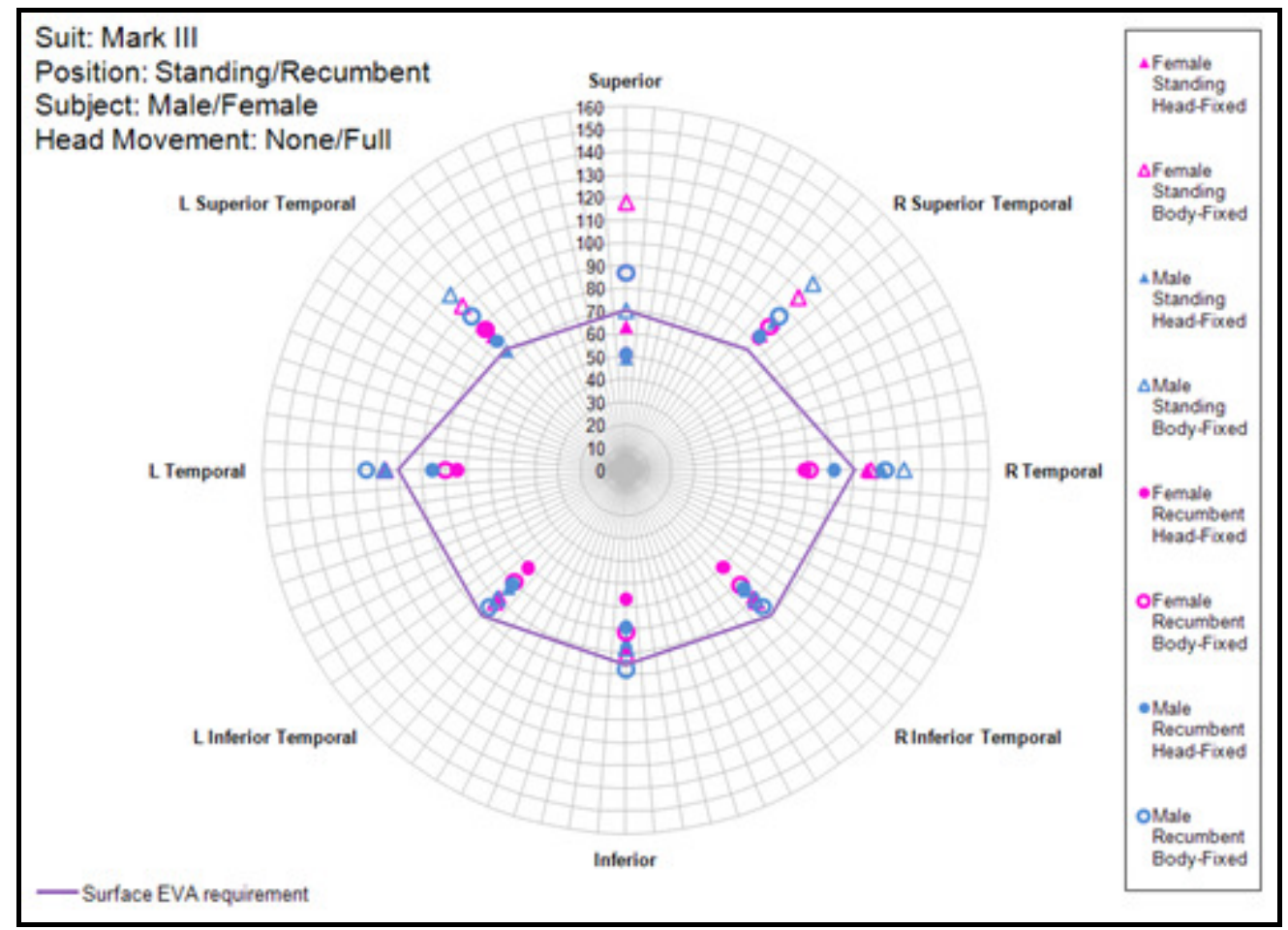

Figure 25: Mark III compared to Constellation FOV Requirement

Lastly, the D-Suit can be compared against Constellation requirements as well. The best analog is the LEA, emergency egress, and microgravity EVA requirements, as the Constellation Configuration 1 suit will be designed for these mission segments. This comparison is shown below in Figure 26.

Against the LEA requirement (shown in orange), the DSuit performs very well for all cases and directions, surpassing the requirement even without head rotation.

When compared to the microgravity EVA requirement (shown in purple), the D-Suit meets the requirement in all temporal cases and most superior cases. Allowing for head rotation, all superior cases are met. In the inferior directions, the requirement is met when providing for head rotation as well.

The emergency egress requirement (in green), which is the most expansive field of view required of the
Constellation suit, is again, easily met in the temporal directions. The D-Suit meets or comes very close to meeting the field of view in the inferior directions, which is a big improvement over the other suits.

The superior temporal directions are met through head rotation; however the superior field of view does not meet the requirement. This is most likely due to the design of the neck wedge, which precluded the test subjects from rotating their heads enough to meet the requirement. In other words, the helmet was not blocking the required viewing angle in the superior direction; it was preventing ample head rotation to facilitate viewing the angle due to a specific design feature.

To wit, the Mark III helmet provided, above the standing head-fixed state, an additional 37.8 degrees of superior field of view through head motion while the D-Suit only allowed 13.9 degrees (average of male and female subjects). 


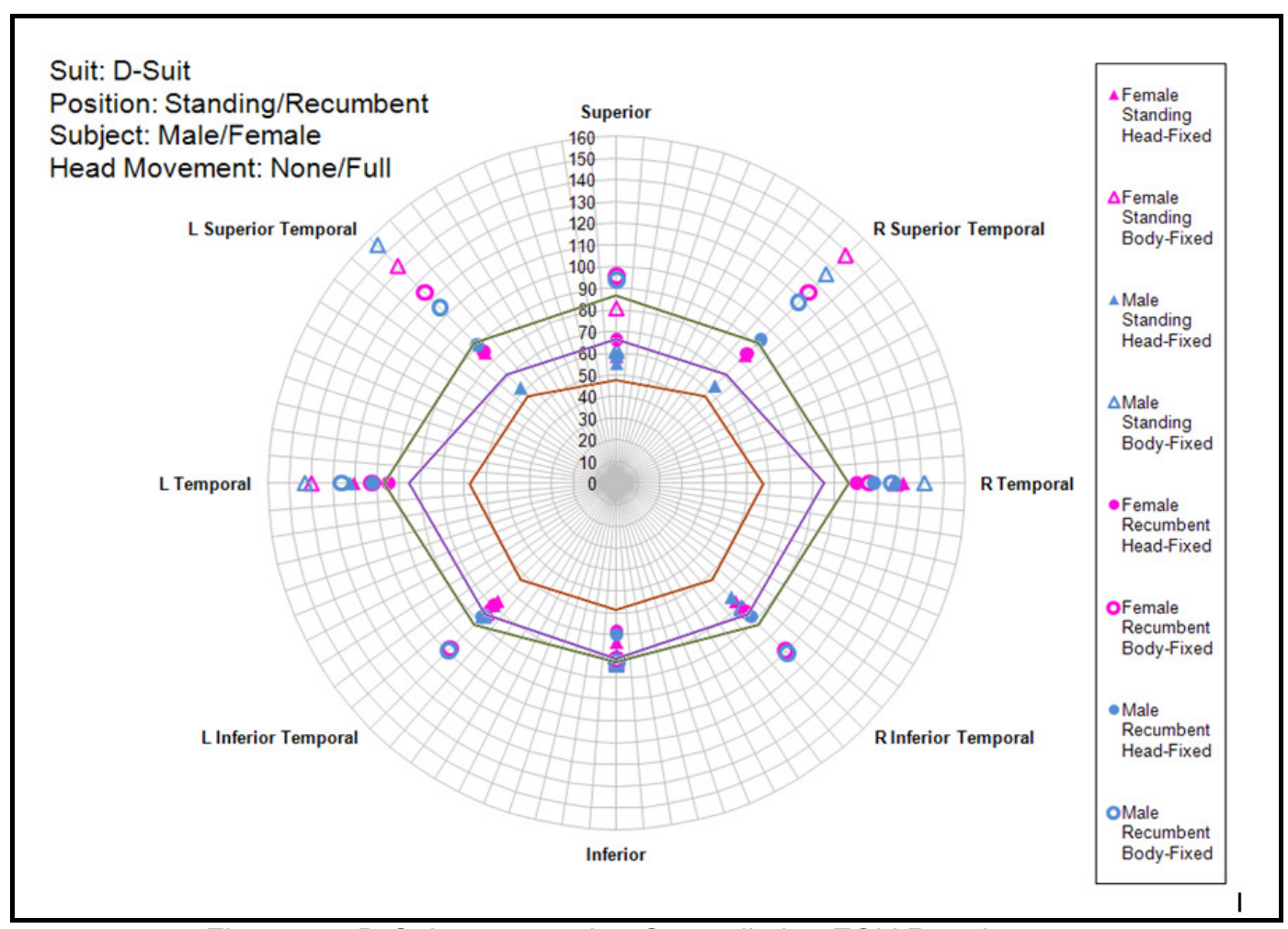

Figure 26: D-Suit compared to Constellation FOV Requirement

\section{CONCLUSION}

This test collected field of view data from four different suits: the Advanced Crew Escape Suit [ACES]; the 1031 Pilot's Protective Assembly [PPA]; the Mark III Lunar Prototype; the D-Suit (with neck wedge attachment).

By gathering data from two subjects in different body positions (standing/recumbent) and head movements (none/full), this test was the most comprehensive field of view test ever performed at NASA. It provides a test bed for future field of view evaluations of previous, current and future NASA suit hardware and has shown to have documented, repeatable results with which comparisons and correlations across relevant variables can be made.

This test also demonstrated that the assumed correlation between head size and field of view is not always an accurate one, and at times field of view is more dependent on specific facial geometry such as the brow, nose, and eye sockets than the overall size of the head.

Lastly, this test demonstrates how current and previous suits perform with respect to field of view and the new Constellation field of view requirement, which is more difficult to meet than previous NASA programs. The data from this and subsequent tests can be used to correlate specific suit and helmet design features or geometry, with impacts to crewmember field of view.

This test found that of the four suits tested, the D-Suit was by far the closest to meeting the new Constellation requirement. This suit's only limitation as far as field of view is concerned was superior viewing, where the standing subject had difficulty rotating their heads enough due to the neck wedge design. If, perhaps, this neck wedge was redesigned with the same interfaces and bubble helmet but with slightly different wedge geometry, the D-Suit may easily meet the Constellation requirement in all directions and cases.

It should be noted, however, the degree of difficulty associated with designing a helmet for optimal field of view, whiles also meeting other requirements, such as occupant head protection, a visor opening mechanism, etc. The D-Suit was not designed with either of these requirements in mind, yet the Constellation suit will need to meet these and other requirements in addition to the field of view requirement.

This trade between field of view and other requirements has been, and will continue to be a major engineering challenge in the years to come when designing NASA's Constellation Program Space Suit. 


\section{REFERENCES}

(1) "S1010D Visibility Test." David Clark Company, 16Aug-1979.

(2) "TP-2007-214754, Wearability, Comfort and Field of View Findings from the Integrated Launch Suit Test." JSC, Houston: NASA, Jan. 2008.

(3) Joseph Kosmo (NASA). Phone Correspondence. 15-Jan-2010.

(4) "Goldmann Visual Fields: A Technician's Guide." Association of Technical Personnel in Ophthalmology (ATPO), St. Paul, MN.

(5) "Field of Vision: A Manual and Atlas of Perimetry." Barton, J. J. S. \& Benetar, M. Humana Press, Totowa, NJ, 2003.

(6) "CxP 72208, Constellation Space Suit Element Requirements Document Rev C. JSC, Houston: NASA, 10-Dec-2009.

(7) "S1030 Visibility Test." David Clark Company, 22Aug-1979.

(8) "JSC-25909, Crew Systems Reference Manual: Volume 1 - Crew Escape." JSC, Houston: NASA, 30Nov-2001.

(9) "Anatomy and Physiology: The Unity of Form and Function." Saladin, K. $4^{\text {th }}$ ed. McGraw Hill, New York, NY, 2007.

(10) "3D Perception CompactView SX+40 User Manual." 3D Perception, Inc, Orlando, FL, 2008.

(11) "SAE 2009-01-2496, Defining Constellation Suit Helmet Field of View Requirements Employing a Mission Segment Based Reduction Process." McFarland, S. JSC, Houston: NASA, 2009.

(12) "JSC-23003, Specification Assembly Drawing Part II for the Crew Escape Equipment, Rev G." JSC, Houston: NASA, 8-Dec-2000.

(13) "1988 Anthropometric Survey of U.S. Army Personnel." Science and Advanced Technology Directorate, Natick: US DoD: Mar. 1989.

\section{CONTACT}

Shane M. McFarland currently works at NASA Johnson Space Center as a Senior Project Engineer on the Constellation Space Suit Pressure Garment Subsystem. His education is in Physics, Mechanical Engineering, Aerospace Engineering and Bioastronautics. He can be reached at shane.m.mcfarland@nasa.gov. 


\section{DEFINITIONS, ACRONYMS, ABBREVIATIONS}

ACES: Advanced Crew Escape Suit

EVA: Extra-Vehicular Activity

FOV: Field of View

HRA: Helmet Retention Assembly

LEA: Launch, Entry, Abort

PPA: Pilot's Protective Assembly 


\section{APPENDIX A: SUBJECT ANTHROPOMETRY}

The anthropometric features of each subject's head were measured before beginning the test series. Each subject either had perfect natural or corrected vision. The percentile values and corresponding reference in the last column are taken from the 1988 Anthropometric Survey of U.S. Army Personnel (13).

\begin{tabular}{|l|c|c|c|c|c|}
\hline Anthropometric Measurement & Female (in) & Percentile & Male (in) & Percentile & US Army Ref \\
\hline Standing Eye Height & 61.75 & n/a & 66.75 & n/a & 62 \\
\hline Head Length & 7.68 & 89 th & 8.50 & 99 th & 61 \\
\hline Head Circumference at nose bridge (above ear) & 22.25 & $91 \mathrm{st}$ & 23.25 & $92 \mathrm{nd}$ & 68 \\
\hline Interpupillary Breadth & 2.48 & 60 th & 2.95 & 99 th & 6 \\
\hline Head height & 8.66 & n/a & 9.65 & n/a & 77 \\
\hline Chin-to-pupil height & 4.29 & 25 th & 4.92 & 70 th & 77 \\
\hline
\end{tabular}

Figure A1: Subject Anthropometry Tables 
The field of view data shown below assumes a left-to-right symmetry, and is a product of averaging the final left and right values for each applicable major field of view direction (superior temporal, temporal and inferior temporal).

\begin{tabular}{|c|c|c|c|c|c|c|c|c|c|c|c|c|c|c|c|c|c|}
\hline \multirow{2}{*}{\multicolumn{2}{|c|}{$\begin{array}{l}\text { Symmetrical Directions Averaged } \\
M=\text { male; } F=\text { female } \\
H F=\text { head fixed; } B F=\text { body fixed }\end{array}$}} & \multicolumn{16}{|c|}{ STANDING ** STANDING ** STANDING ** STANDING ** STANDING ** STANDING } \\
\hline & & \multirow[t]{2}{*}{$\begin{array}{l}\text { D-Suit } \\
\text { [F/HF] }\end{array}$} & \multirow[t]{2}{*}{$\begin{array}{l}\text { D-Suit } \\
\text { [F/BF] }\end{array}$} & \multirow[t]{2}{*}{$\begin{array}{c}\text { D-Suit } \\
\text { [M/HF] }\end{array}$} & \multirow[t]{2}{*}{$\begin{array}{l}\text { D-Suit } \\
\text { [M/BF] }\end{array}$} & \multirow[t]{2}{*}{$\begin{array}{c}1031 \\
{[\mathrm{~F} / \mathrm{HF}]}\end{array}$} & \multirow[t]{2}{*}{$\begin{array}{c}1031 \\
{[F / B F]}\end{array}$} & \multirow[t]{2}{*}{$\begin{array}{c}1031 \\
{[\mathrm{M} / \mathrm{HF}]}\end{array}$} & \multirow[t]{2}{*}{$\begin{array}{c}1031 \\
{[\mathrm{M} / \mathrm{BF}]}\end{array}$} & \multirow[t]{2}{*}{$\begin{array}{c}\text { MK3 } \\
{[\mathrm{F} / \mathrm{HF}]}\end{array}$} & \multirow[t]{2}{*}{$\begin{array}{c}\text { MK3 } \\
{[\mathrm{F} / \mathrm{BF}]}\end{array}$} & \multirow[t]{2}{*}{$\begin{array}{c}\mathrm{MK3} \\
{[\mathrm{M} / \mathrm{HF}]}\end{array}$} & \multirow[t]{2}{*}{$\begin{array}{c}\mathrm{MK3} \\
{[\mathrm{M} / \mathrm{BF}]}\end{array}$} & \multirow[t]{2}{*}{$\begin{array}{c}\text { ACES } \\
{[\mathrm{F} / \mathrm{HF}]}\end{array}$} & \multirow[t]{2}{*}{$\begin{array}{c}\text { ACES } \\
{[\mathrm{F} / \mathrm{BF}]}\end{array}$} & \multirow[t]{2}{*}{$\begin{array}{c}\text { ACES } \\
{[\mathrm{M} / \mathrm{HF}]}\end{array}$} & \multirow[t]{2}{*}{$\begin{array}{c}\text { ACES } \\
{[\mathrm{M} / \mathrm{BF}]}\end{array}$} \\
\hline FOV Angle Name & Ang & & & & & & & & & & & & & & & & \\
\hline Superior & 0 & 58.6 & 80.8 & 55.5 & 61.0 & 43.8 & 54.5 & 46.8 & 71.1 & 63.0 & 117.6 & 49.2 & 70.2 & 60.4 & 61.2 & 57.2 & 68.1 \\
\hline R Superior Temporal & 45 & 84.3 & 145.5 & 63.0 & 145.7 & 58.3 & 146.4 & 73.2 & 153.7 & 83.4 & 104.7 & 83.2 & 112.6 & 77.8 & 79.5 & 81.8 & 82.8 \\
\hline R Temporal & 90 & 125.8 & 134.1 & 124.8 & 142.3 & 87.6 & 153.7 & 96.9 & 151.8 & 105.6 & 107.1 & 109.1 & 114.3 & 111.4 & 108.6 & 108.7 & 112.1 \\
\hline R Inferior Temporal & 135 & 77.1 & 83.3 & 77.0 & 83.8 & 68.7 & 85.5 & 68.4 & 89.5 & 78.8 & 81.4 & 73.9 & 80.3 & 66.8 & 84.6 & 71.1 & 91.4 \\
\hline Inferior & 180 & 73.4 & 82.4 & 78.9 & 83.6 & 69.2 & 88.4 & 71.6 & 89.5 & 77.9 & 80.6 & 75.2 & 78.6 & 67.7 & 88.2 & 71.0 & 94.3 \\
\hline L Inferior Temporal & 225 & 77.1 & 83.3 & 77.0 & 83.8 & 68.7 & 85.5 & 68.4 & 89.5 & 78.8 & 81.4 & 73.9 & 80.3 & 66.8 & 84.6 & 71.1 & 91.4 \\
\hline L Temporal & 270 & 125.8 & 134.1 & 124.8 & 142.3 & 87.6 & 153.7 & 96.9 & 151.8 & 105.6 & 107.1 & 109.1 & 114.3 & 111.4 & 108.6 & 108.7 & 112.1 \\
\hline L Superior Temporal & 315 & 84.3 & 145.5 & 63.0 & 145.7 & 58.3 & 146.4 & 73.2 & 153.7 & 83.4 & 104.7 & 83.2 & 112.6 & 77.8 & 79.5 & 81.8 & 82.8 \\
\hline
\end{tabular}

Figure A2: Standing Symmetrical FOV Data

\begin{tabular}{|c|c|c|c|c|c|c|c|c|c|c|c|c|c|c|c|c|c|}
\hline \multirow{2}{*}{\multicolumn{2}{|c|}{$\begin{array}{l}\text { Symmetrical Directions Averaged } \\
M=\text { male; } F=\text { female } \\
H F=\text { head fixed; } B F=\text { body fixed }\end{array}$}} & \multicolumn{16}{|c|}{ RECUMBENT ** RECUMBENT ** RECUMBENT ** RECUMBENT ** RECUMBENT ** RECUMBENT } \\
\hline & & \multirow[t]{2}{*}{$\begin{array}{l}\text { D-Suit } \\
\text { [F/HF] }\end{array}$} & \multirow[t]{2}{*}{$\begin{array}{l}\text { D-Suit } \\
\text { [F/BF] }\end{array}$} & \multirow[t]{2}{*}{$\begin{array}{l}\text { D-Suit } \\
{[\mathrm{M} / \mathrm{HF}]}\end{array}$} & \multirow[t]{2}{*}{$\begin{array}{c}\text { D-Suit } \\
{[\mathrm{M} / \mathrm{BF}]}\end{array}$} & \multirow[t]{2}{*}{$\begin{array}{c}1031 \\
{[\mathrm{~F} / \mathrm{HF}]}\end{array}$} & \multirow[t]{2}{*}{$\begin{array}{c}1031 \\
{[\mathrm{~F} / \mathrm{BF}]}\end{array}$} & \multirow[t]{2}{*}{$\begin{array}{c}1031 \\
{[\mathrm{M} / \mathrm{HF}]}\end{array}$} & \multirow[t]{2}{*}{$\begin{array}{c}1031 \\
{[\mathrm{M} / \mathrm{BF}]}\end{array}$} & \multirow[t]{2}{*}{$\begin{array}{c}\text { MK3 } \\
{[\mathrm{F} / \mathrm{HF}]}\end{array}$} & \multirow[t]{2}{*}{$\begin{array}{c}\text { MK3 } \\
{[\mathrm{F} / \mathrm{BF}]}\end{array}$} & \multirow[t]{2}{*}{$\begin{array}{c}\text { MK3 } \\
{[\mathrm{M} / \mathrm{HF}]}\end{array}$} & \multirow[t]{2}{*}{$\begin{array}{c}\text { MK3 } \\
{[\mathrm{M} / \mathrm{BF}]}\end{array}$} & \multirow[t]{2}{*}{$\begin{array}{c}\text { ACES } \\
{[\mathrm{F} / \mathrm{HF}]}\end{array}$} & \multirow[t]{2}{*}{$\begin{array}{c}\text { ACES } \\
{[\mathrm{F} / \mathrm{BF}]}\end{array}$} & \multirow[t]{2}{*}{$\begin{array}{c}\text { ACES } \\
{[\mathrm{M} / \mathrm{HF}]}\end{array}$} & \multirow[t]{2}{*}{$\begin{array}{c}\text { ACES } \\
{[\mathrm{M} / \mathrm{BF}]}\end{array}$} \\
\hline FOV Angle Name & Ang & & & & & & & & & & & & & & & & \\
\hline Superior & 0 & 66.1 & 95.7 & 58.1 & 93.7 & 32.9 & 34.2 & 52.3 & 63.4 & 61.7 & 91.4 & 50.9 & 87.2 & 56.6 & 79.3 & 63.2 & 81.4 \\
\hline R Superior Temporal & 45 & 85.2 & 124.5 & 92.0 & 116.3 & 47.4 & 110.7 & 72.5 & 112.1 & 85.4 & 88.5 & 81.8 & 95.8 & 85.5 & 96.2 & 94.7 & 88.3 \\
\hline R Temporal & 90 & 107.4 & 114.1 & 115.0 & 126.4 & 81.5 & 153.7 & 88.3 & 135.0 & 76.7 & 80.1 & 88.5 & 114.1 & 113.3 & 132.0 & 110.2 & 132.8 \\
\hline R Inferior Temporal & 135 & 81.8 & 108.8 & 87.2 & 110.0 & 83.3 & 113.9 & 72.6 & 112.5 & 60.7 & 70.5 & 72.3 & 85.1 & 52.4 & 100.8 & 96.1 & 112.4 \\
\hline Inferior & 180 & 68.4 & 81.6 & 70.1 & 82.8 & 68.4 & 90.4 & 53.3 & 93.2 & 56.7 & 71.1 & 69.1 & 87.5 & 39.6 & 64.2 & 51.5 & 71.6 \\
\hline L Inferior Temporal & 225 & 81.8 & 108.8 & 87.2 & 110.0 & 83.3 & 113.9 & 72.6 & 112.5 & 60.7 & 70.5 & 72.3 & 85.1 & 52.4 & 100.8 & 96.1 & 112.4 \\
\hline L Temporal & 270 & 107.4 & 114.1 & 115.0 & 126.4 & 81.5 & 153.7 & 88.3 & 135.0 & 76.7 & 80.1 & 88.5 & 114.1 & 113.3 & 132.0 & 110.2 & 132.8 \\
\hline L Superior Temporal & 315 & 85.2 & 124.5 & 92.0 & 116.3 & 47.4 & 110.7 & 72.5 & 112.1 & 85.4 & 88.5 & 81.8 & 95.8 & 85.5 & 96.2 & 94.7 & 88.3 \\
\hline
\end{tabular}


The field of view data below shows the field of view from a given head-fixed state (shown in normal black text) and the delta from that test to the same test when head movement is allowed (in red or green bolded text).

\begin{tabular}{|c|c|c|c|c|c|c|c|c|c|c|c|c|c|c|c|c|c|}
\hline \multirow{2}{*}{\multicolumn{2}{|c|}{$\begin{array}{l}\text { Delta from head rotation } \\
M=\text { male; } F=\text { female } \\
H F=\text { head fixed; } B F=\text { body fixed }\end{array}$}} & \multicolumn{16}{|c|}{ STANDING ${ }^{* *}$ STANDING ${ }^{* *}$ STANDING $* *$ STANDING $* *$ STANDING $* *$ STANDING } \\
\hline & & \multirow[t]{2}{*}{$\begin{array}{l}\text { D-Suit } \\
\text { [F/HF] }\end{array}$} & \multirow[t]{2}{*}{$\begin{array}{l}\text { D-Suit } \\
\text { [F/BF] }\end{array}$} & \multirow[t]{2}{*}{$\begin{array}{l}\text { D-Suit } \\
{[\mathrm{M} / \mathrm{HF}]}\end{array}$} & \multirow[t]{2}{*}{$\begin{array}{l}\text { D-Suit } \\
{[\mathrm{M} / \mathrm{BF}]}\end{array}$} & \multirow[t]{2}{*}{$\begin{array}{c}1031 \\
{[\mathrm{~F} / \mathrm{HF}]}\end{array}$} & \multirow[t]{2}{*}{$\begin{array}{c}1031 \\
{[\mathrm{~F} / \mathrm{BF}]}\end{array}$} & \multirow[t]{2}{*}{$\begin{array}{c}1031 \\
{[\mathrm{M} / \mathrm{HF}]}\end{array}$} & \multirow[t]{2}{*}{$\begin{array}{c}1031 \\
{[\mathrm{M} / \mathrm{BF}]}\end{array}$} & \multirow[t]{2}{*}{$\begin{array}{c}\text { MK3 } \\
{[\mathrm{F} / \mathrm{HF}]}\end{array}$} & \multirow[t]{2}{*}{$\begin{array}{c}\text { MK3 } \\
\text { [F/BF] }\end{array}$} & \multirow[t]{2}{*}{$\begin{array}{c}\text { MK3 } \\
{[\mathrm{M} / \mathrm{HF}]}\end{array}$} & \multirow[t]{2}{*}{$\begin{array}{c}\text { MK3 } \\
{[\mathrm{M} / \mathrm{BF}]}\end{array}$} & \multirow[t]{2}{*}{$\begin{array}{c}\text { ACES } \\
{[\mathrm{F} / \mathrm{HF}]}\end{array}$} & \multirow[t]{2}{*}{$\begin{array}{c}\text { ACES } \\
\text { [F/BF] }\end{array}$} & \multirow[t]{2}{*}{$\begin{array}{c}\text { ACES } \\
{[\mathrm{M} / \mathrm{HF}]}\end{array}$} & \multirow[t]{2}{*}{$\begin{array}{c}\text { ACES } \\
{[\mathrm{M} / \mathrm{BF}]}\end{array}$} \\
\hline FOV Angle Name & Ang & & & & & & & & & & & & & & & & \\
\hline Superior & 0 & 58.6 & +22.2 & 55.5 & +5.5 & 43.8 & +10.7 & 46.8 & +24.3 & 63.0 & +54.6 & 49.2 & +20.9 & 60.4 & +.8 & 57.2 & $+\mathbf{1 1 . 0}$ \\
\hline R Superior Temporal & 45 & 83.4 & +65.5 & 63.7 & +72.5 & 58.4 & +86.1 & 74.8 & +83.4 & 83.8 & +23.5 & 91.9 & +24.2 & 85.1 & -1.0 & 84.1 & -1.6 \\
\hline R Temporal & 90 & 131.3 & -3.1 & 127.2 & +14.3 & 87.6 & +69.4 & 98.4 & +55.8 & 105.9 & +1.9 & 112.7 & +9.5 & 115.8 & -1.0 & 106.7 & +2.3 \\
\hline R Inferior Temporal & 135 & 77.2 & +5.4 & 74.3 & +6.9 & 67.6 & +19.1 & 64.7 & +23.9 & 78.9 & +2.3 & 74.5 & +6.0 & 65.6 & +18.2 & 70.5 & +25.0 \\
\hline Inferior & 180 & 73.4 & +9.0 & 78.9 & +4.8 & 69.2 & +19.2 & 71.6 & +17.9 & 77.9 & +2.7 & 75.2 & +3.4 & 67.7 & +20.5 & 71.0 & +23.3 \\
\hline L Inferior Temporal & 225 & 76.9 & +7.2 & 79.7 & +6.6 & 69.7 & +14.6 & 72.2 & +18.3 & 78.6 & +3.0 & 73.3 & +6.8 & 68.0 & +17.3 & 71.8 & +15.6 \\
\hline L Temporal & 270 & 120.3 & +19.8 & 122.4 & +20.8 & 87.6 & +62.8 & 95.3 & +54.1 & 105.3 & +.9 & 105.6 & +.9 & 107.1 & -4.8 & 110.7 & +4.5 \\
\hline L Superior Temporal & 315 & 85.1 & +56.9 & 62.3 & +92.9 & 58.3 & +89.9 & 71.6 & +77.7 & 82.9 & +19.2 & 74.4 & +34.8 & 70.4 & +4.4 & 79.6 & +3.4 \\
\hline
\end{tabular}

Figure A4: Standing FOV Delta from Head Rotation

\begin{tabular}{|c|c|c|c|c|c|c|c|c|c|c|c|c|c|c|c|c|c|}
\hline \multirow{2}{*}{\multicolumn{2}{|c|}{$\begin{array}{l}\text { Delta from head rotation } \\
M=\text { male; } F=\text { female } \\
H F=\text { head fixed; } B F=\text { body fixed }\end{array}$}} & \multicolumn{16}{|c|}{ RECUMBENT ${ }^{* *}$ RECUMBENT ${ }^{* *}$ RECUMBENT ${ }^{* *}$ RECUMBENT ${ }^{* *}$ RECUMBENT ${ }^{* *}$ RECUMBENT } \\
\hline & & \multirow[t]{2}{*}{$\begin{array}{l}\text { D-Suit } \\
\text { [F/HF }]\end{array}$} & \multirow[t]{2}{*}{$\begin{array}{l}\text { D-Suit } \\
\text { [F/BF] }\end{array}$} & \multirow[t]{2}{*}{$\begin{array}{l}\text { D-Suit } \\
{[\mathrm{M} / \mathrm{HF}]}\end{array}$} & \multirow[t]{2}{*}{$\begin{array}{l}\text { D-Suit } \\
\text { [M/BF] }\end{array}$} & \multirow[t]{2}{*}{$\begin{array}{c}1031 \\
{[\mathrm{~F} / \mathrm{HF}]}\end{array}$} & \multirow[t]{2}{*}{$\begin{array}{c}1031 \\
{[\mathrm{~F} / \mathrm{BF}]}\end{array}$} & \multirow[t]{2}{*}{$\begin{array}{c}1031 \\
{[\mathrm{M} / \mathrm{HF}]}\end{array}$} & \multirow[t]{2}{*}{$\begin{array}{c}1031 \\
{[\mathrm{M} / \mathrm{BF}]}\end{array}$} & \multirow[t]{2}{*}{$\begin{array}{c}\text { MK3 } \\
{[\mathrm{F} / \mathrm{HF}]}\end{array}$} & \multirow[t]{2}{*}{$\begin{array}{c}\text { MK3 } \\
{[\mathrm{F} / \mathrm{BF}]}\end{array}$} & \multirow[t]{2}{*}{$\begin{array}{c}\text { MK3 } \\
{[\mathrm{M} / \mathrm{HF}]}\end{array}$} & \multirow[t]{2}{*}{$\begin{array}{c}\text { MK3 } \\
{[\mathrm{M} / \mathrm{BF}]}\end{array}$} & \multirow[t]{2}{*}{$\begin{array}{c}\text { ACES } \\
{[\mathrm{F} / \mathrm{HF}]}\end{array}$} & \multirow[t]{2}{*}{$\begin{array}{c}\text { ACES } \\
\text { [F/BF] }\end{array}$} & \multirow[t]{2}{*}{$\begin{array}{c}\text { ACES } \\
{[\mathrm{M} / \mathrm{HF}]}\end{array}$} & \multirow[t]{2}{*}{$\begin{array}{c}\text { ACES } \\
{[\mathrm{M} / \mathrm{BF}]}\end{array}$} \\
\hline FOV Angle Name & Ang & & & & & & & & & & & & & & & & \\
\hline Superior & 0 & 66.1 & +29.6 & 58.1 & +35.6 & 32.9 & +1.3 & 52.3 & +11.2 & 61.7 & +29.7 & 50.9 & +36.4 & 56.6 & +22.7 & 63.2 & +18.2 \\
\hline R Superior Temporal & 45 & 84.5 & +40.0 & 93.7 & +24.4 & 46.2 & +67.3 & 76.6 & +37.4 & 82.6 & +6.8 & 83.3 & +12.3 & 82.6 & +15.6 & 97.7 & -7.2 \\
\hline R Temporal & 90 & 110.3 & +5.6 & 118.2 & +8.2 & 79.3 & +77.7 & 87.7 & +47.3 & 78.8 & +2.0 & 91.7 & +22.3 & 115.3 & +16.7 & 112.3 & +20.5 \\
\hline R Inferior Temporal & 135 & 84.0 & +25.6 & 87.2 & +23.7 & 81.7 & +34.5 & 72.5 & +40.7 & 60.6 & +11.0 & 73.6 & +11.2 & 56.9 & +50.3 & 99.4 & +17.3 \\
\hline Inferior & 180 & 68.4 & +13.2 & 70.1 & +12.7 & 68.4 & +22.0 & 53.3 & +39.9 & 56.7 & +14.4 & 69.1 & +18.3 & 39.6 & +24.6 & 51.5 & +20.2 \\
\hline L Inferior Temporal & 225 & 79.5 & +28.4 & 87.1 & +21.9 & 84.9 & +26.8 & 72.7 & +39.1 & 60.9 & +8.6 & 71.0 & +14.3 & 47.9 & +46.5 & 92.9 & +15.3 \\
\hline L Temporal & 270 & 104.6 & +7.7 & 111.9 & +14.5 & 83.8 & +66.6 & 88.8 & +46.2 & 74.5 & +4.8 & 85.3 & +29.0 & 111.2 & +20.8 & 108.2 & +24.6 \\
\hline L Superior Temporal & 315 & 85.9 & +38.6 & 90.3 & +24.2 & 48.7 & +59.2 & 68.4 & +41.8 & 88.2 & -.6 & 80.3 & +15.7 & 88.4 & +5.8 & 91.6 & -5.4 \\
\hline
\end{tabular}




\section{APPENDIX D: SUIT FIELD OF VIEW PERIMETER GRAPHS}

A graph for each of the gender/body position/head rotation variables are available below.

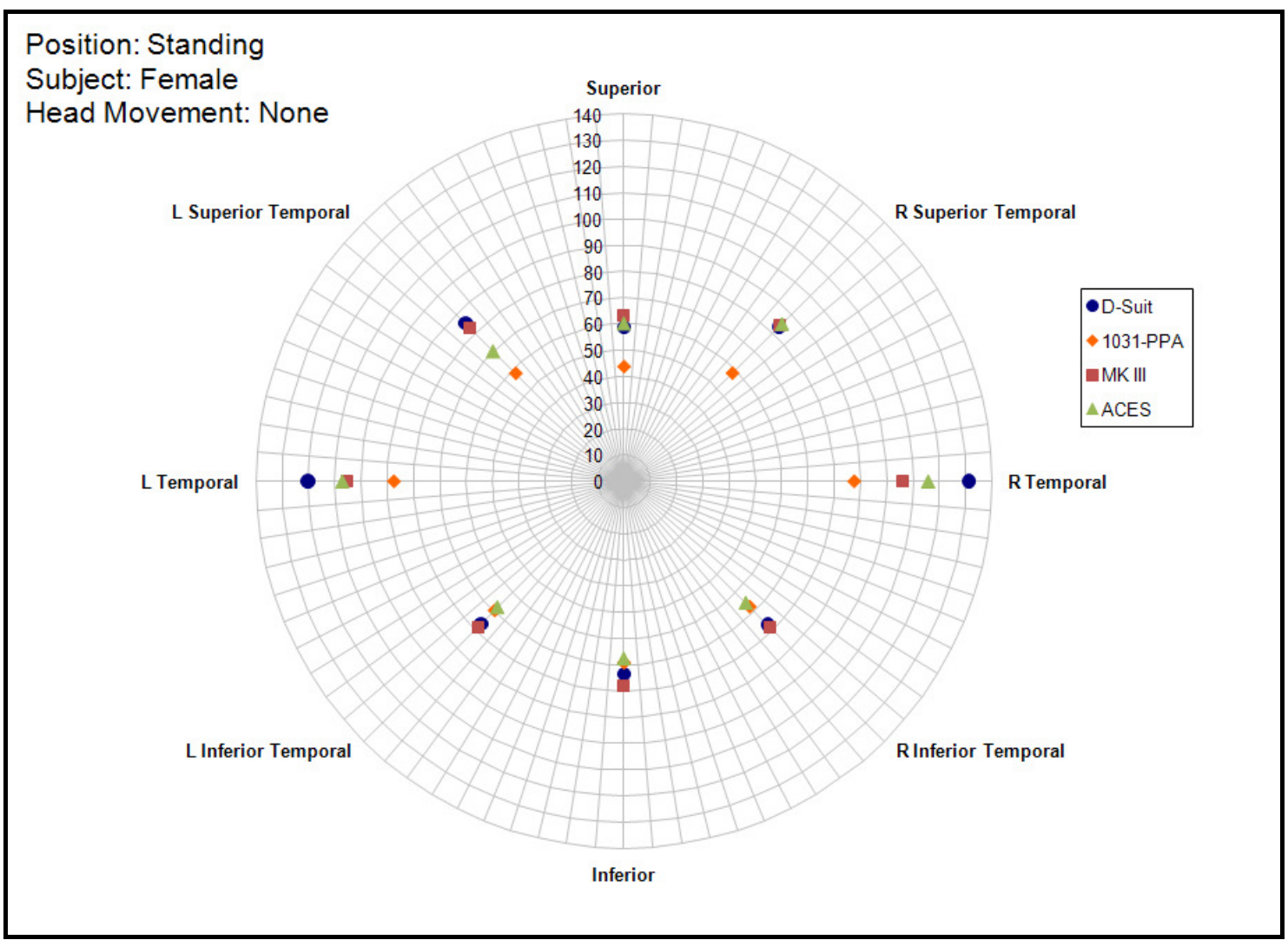

Figure A6: Standing Head-Fixed Female FOV Data

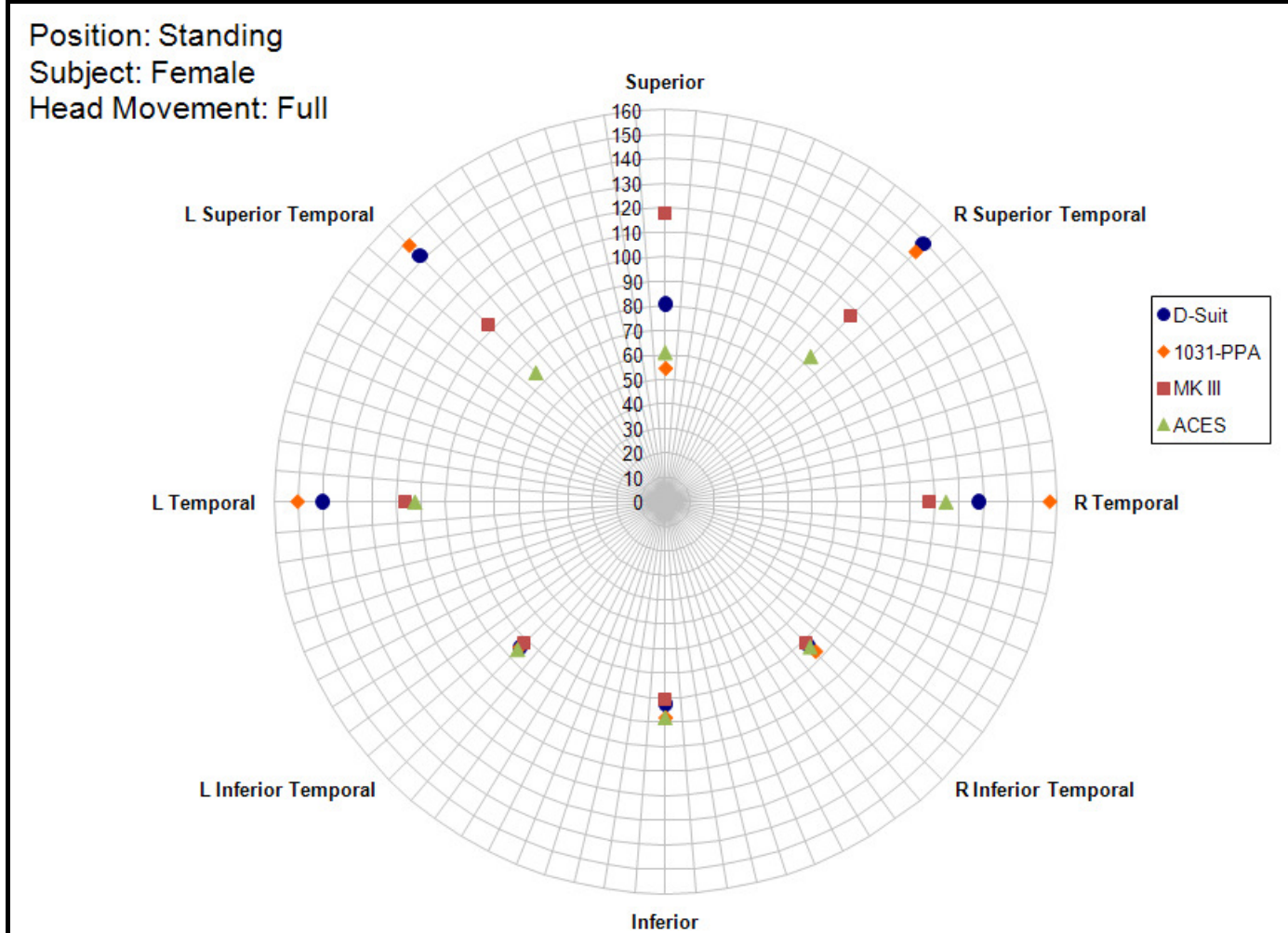

Figure A7: Standing Body-Fixed Female FOV Data 
Position: Standing

Subject: Male

Head Movement: None

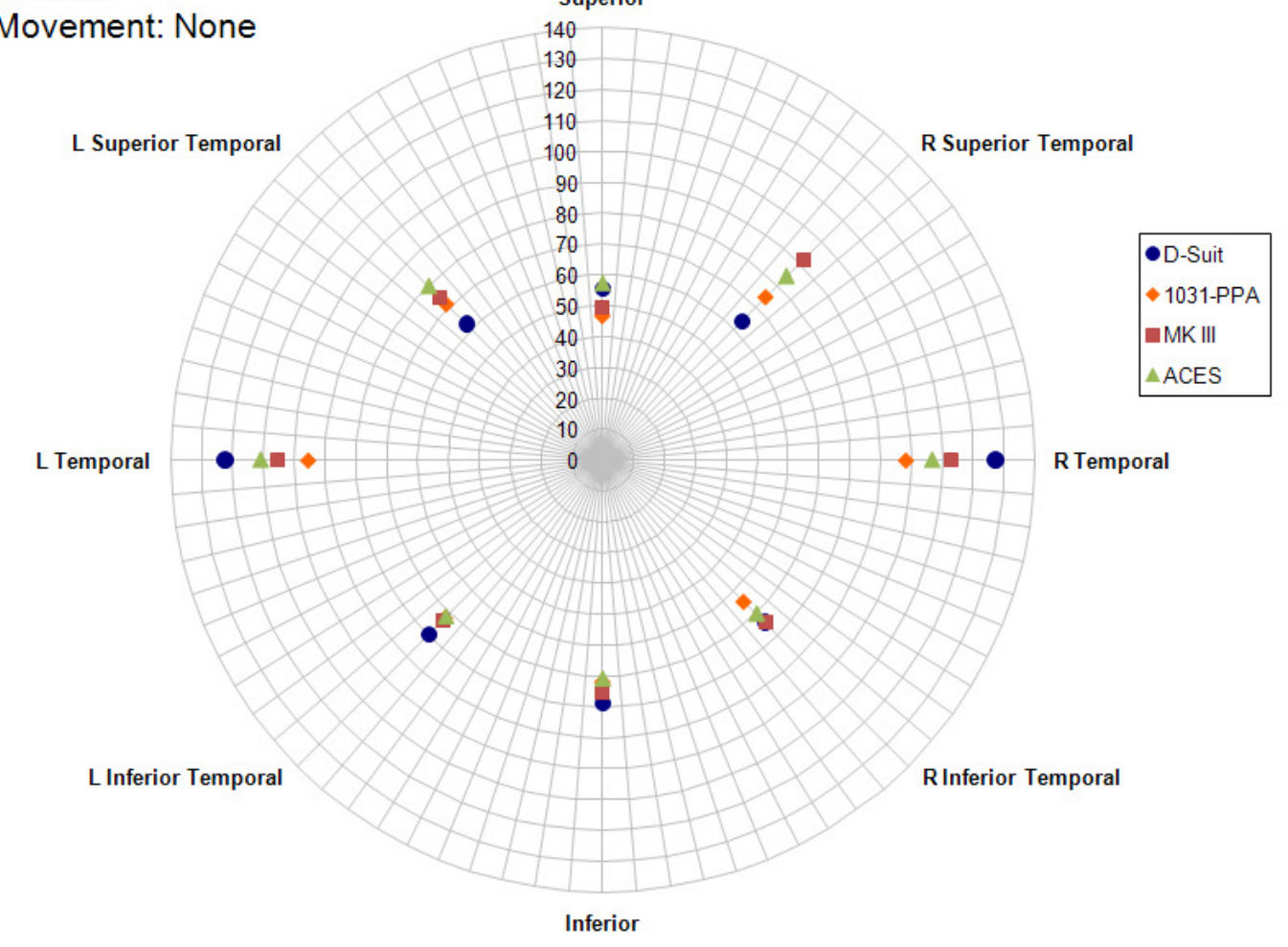

Figure A8: Standing Head-Fixed Male FOV Data

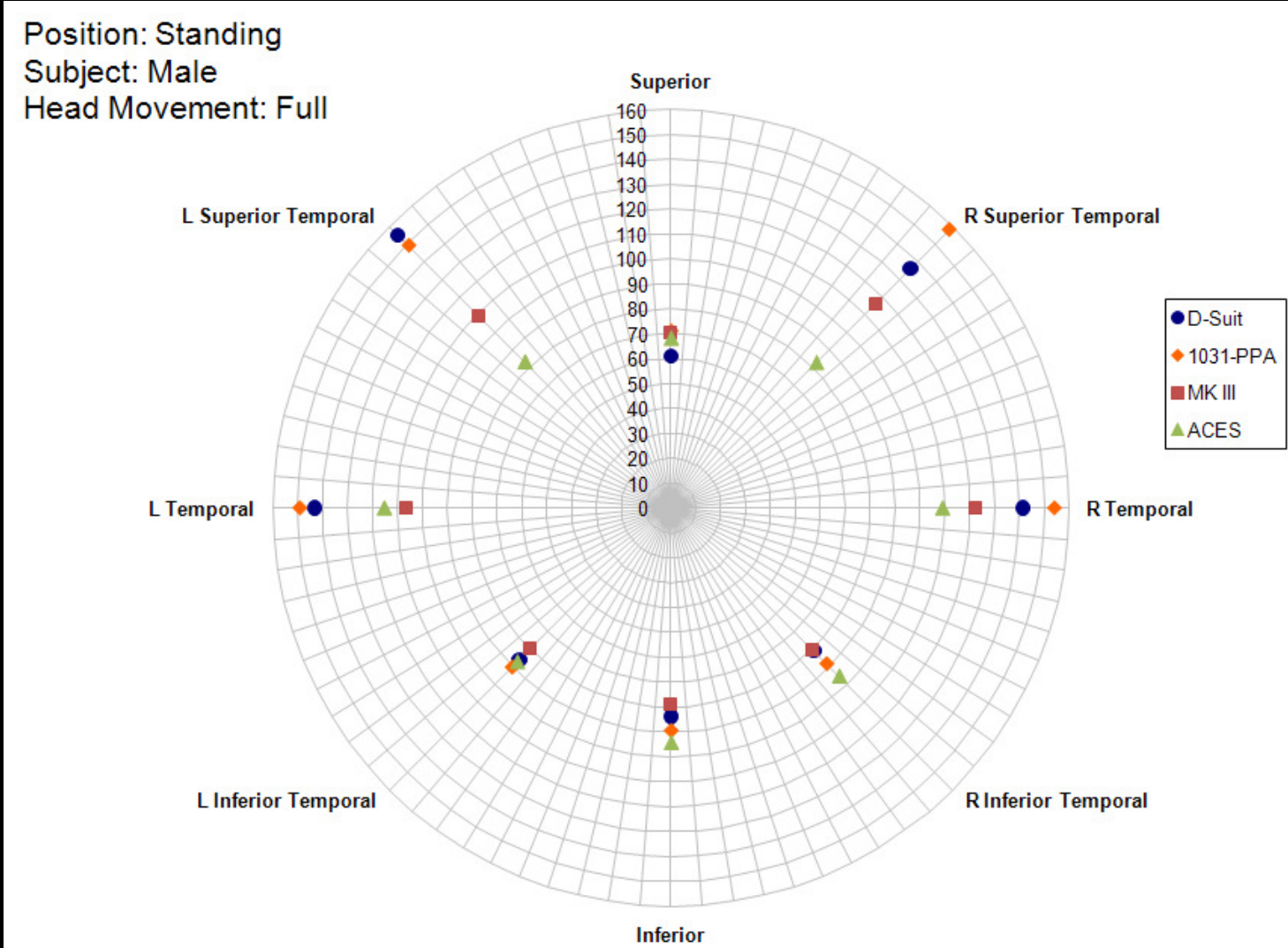

Figure A9: Standing Body-Fixed Male FOV Data 
Position: Recumbent

Subject: Female

Head Movement: None

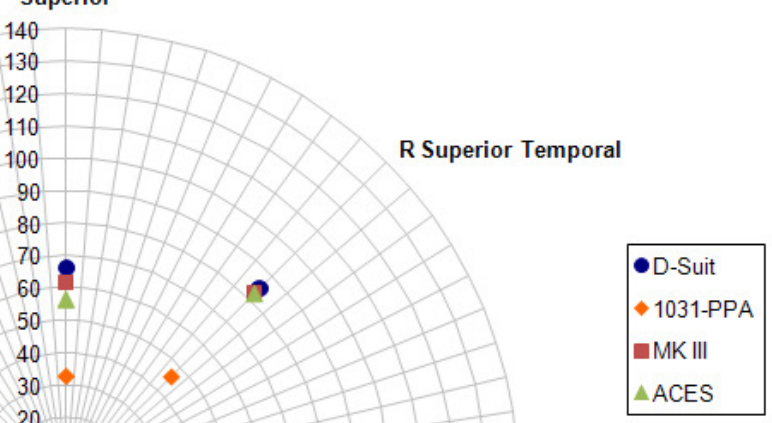

L Temporal

L Superior Temporal

13

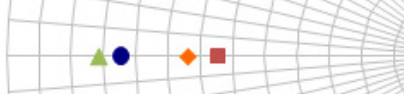

10
0

a

-

R Temporal

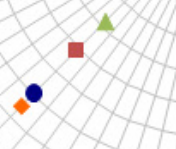

L Inferior Temporal

R Inferior Temporal

4

0

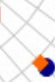

nferior

Figure A10: Recumbent Head-Fixed Female FOV Data

\section{Position: Recumbent}

Subject: Female

Head Movement: Full
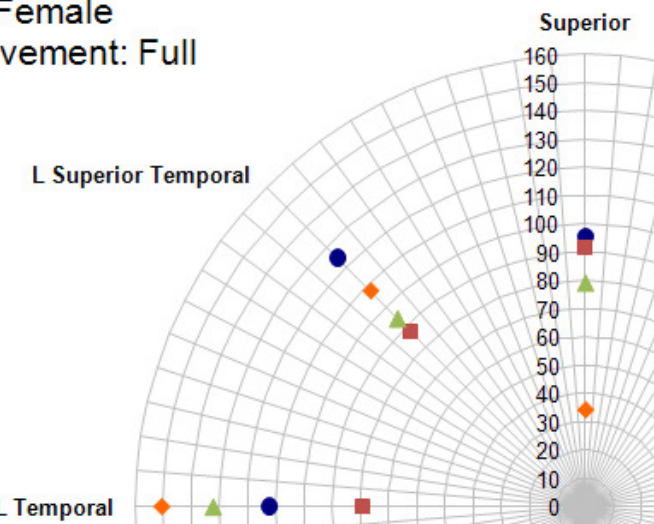

R Superior Temporal
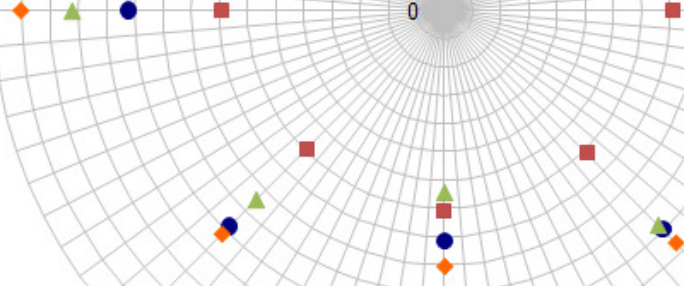

L Inferior Temporal

R Inferior Temporal

\begin{tabular}{|l|}
\hline D-Suit \\
1031-PPA \\
MK III \\
$\triangle$ ACES
\end{tabular}

-

- $\quad$ RTemporal

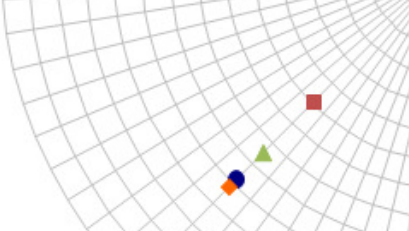

Inferior 
Position: Recumbent

Subject: Male

Head Movement: None

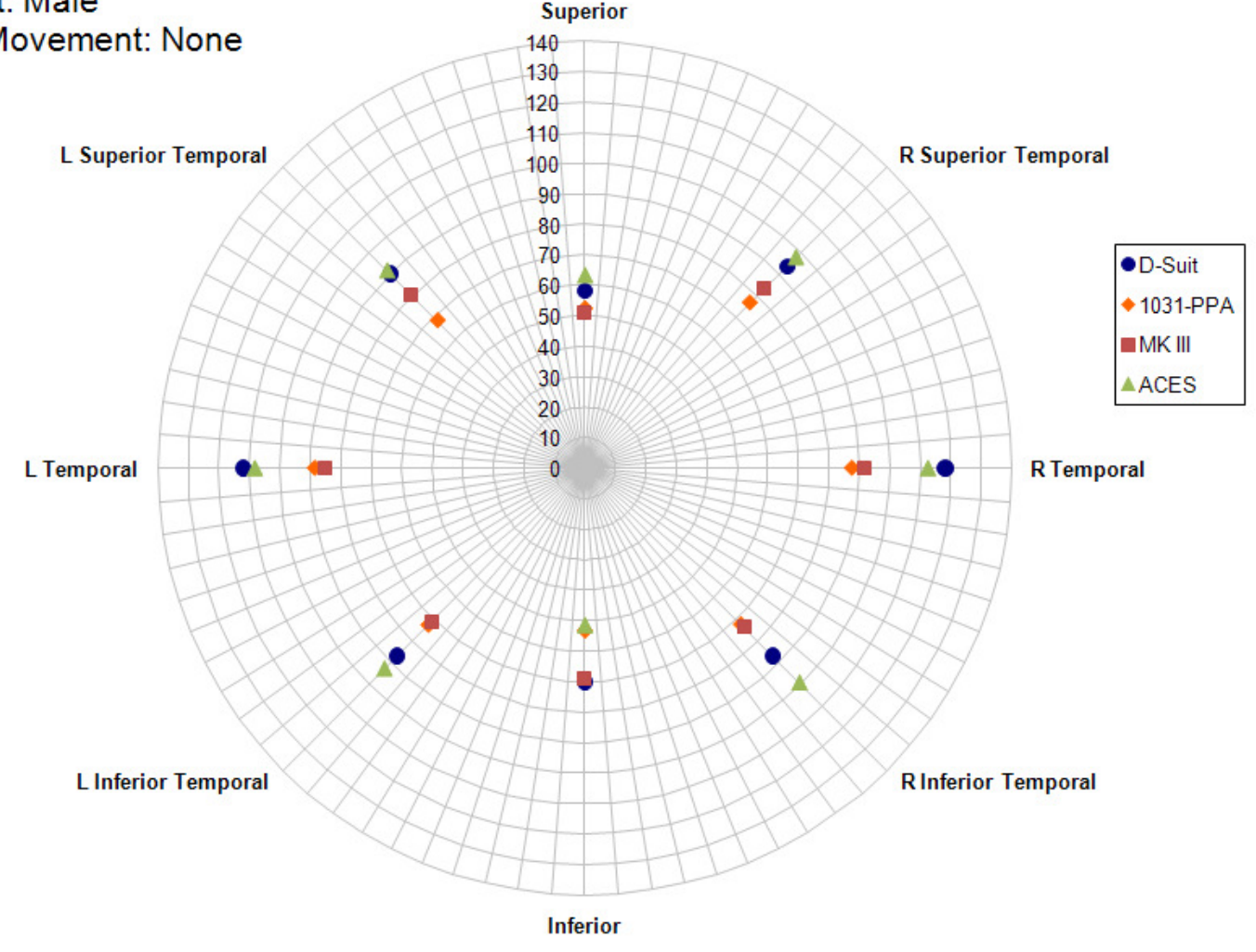

Figure A12: Recumbent Head-Fixed Male FOV Data

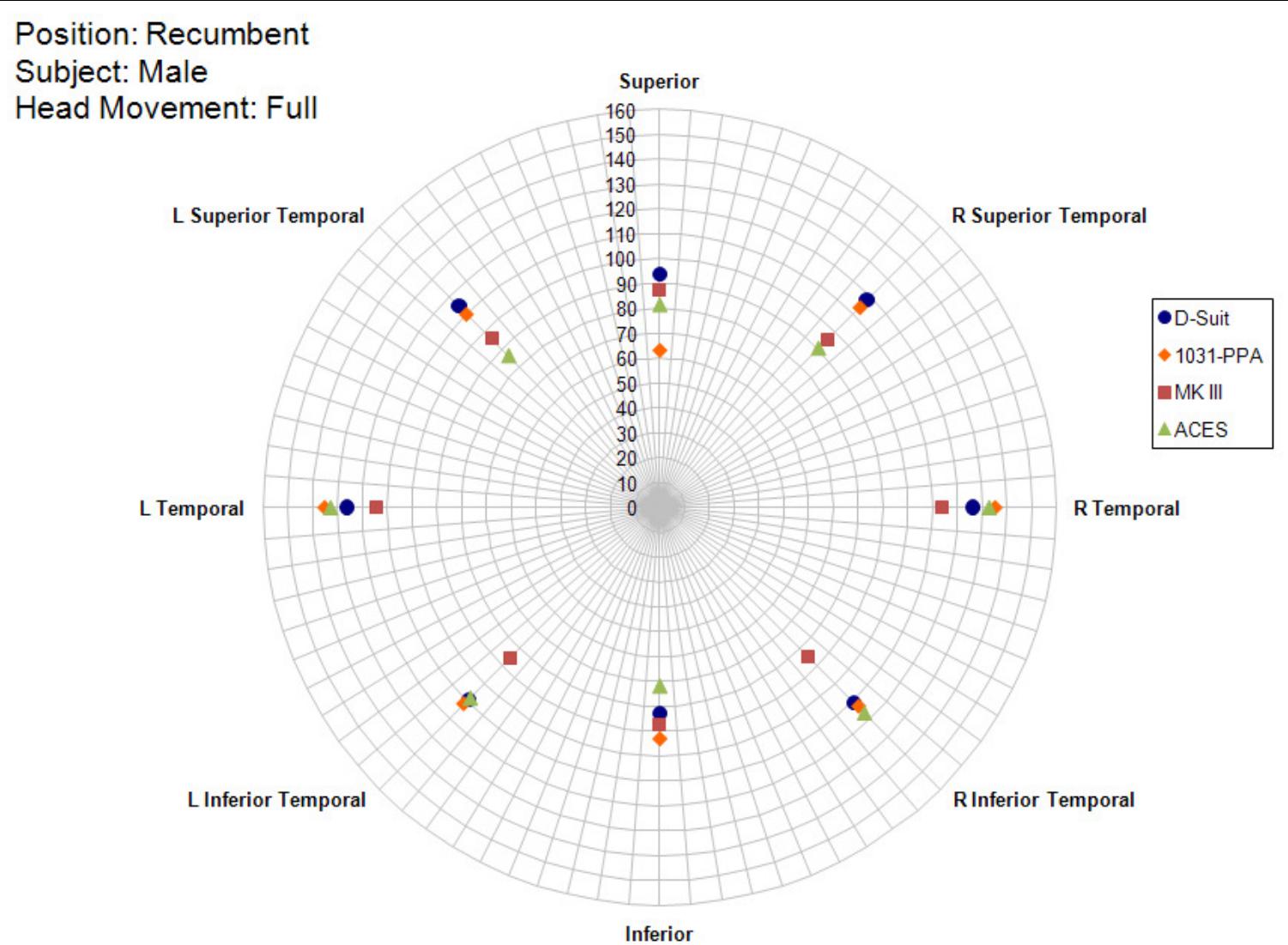

Figure A13: Recumbent Body-Fixed Male FOV Data 


\section{APPENDIX E: SUITED FIELD OF VIEW BY DIRECTION}

A graph of each data point collected per viewing direction is below.

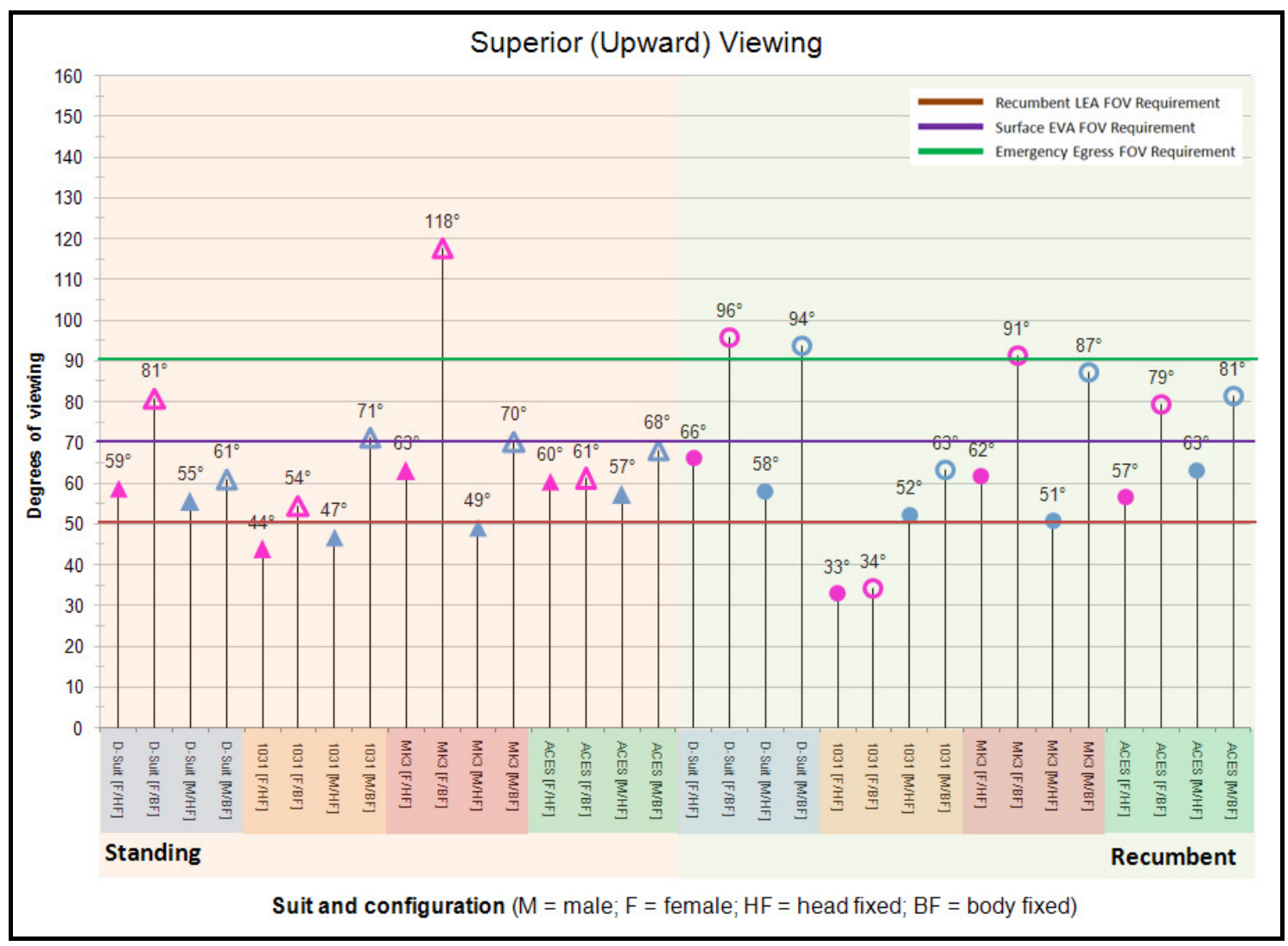

Figure A14: Superior FOV Data

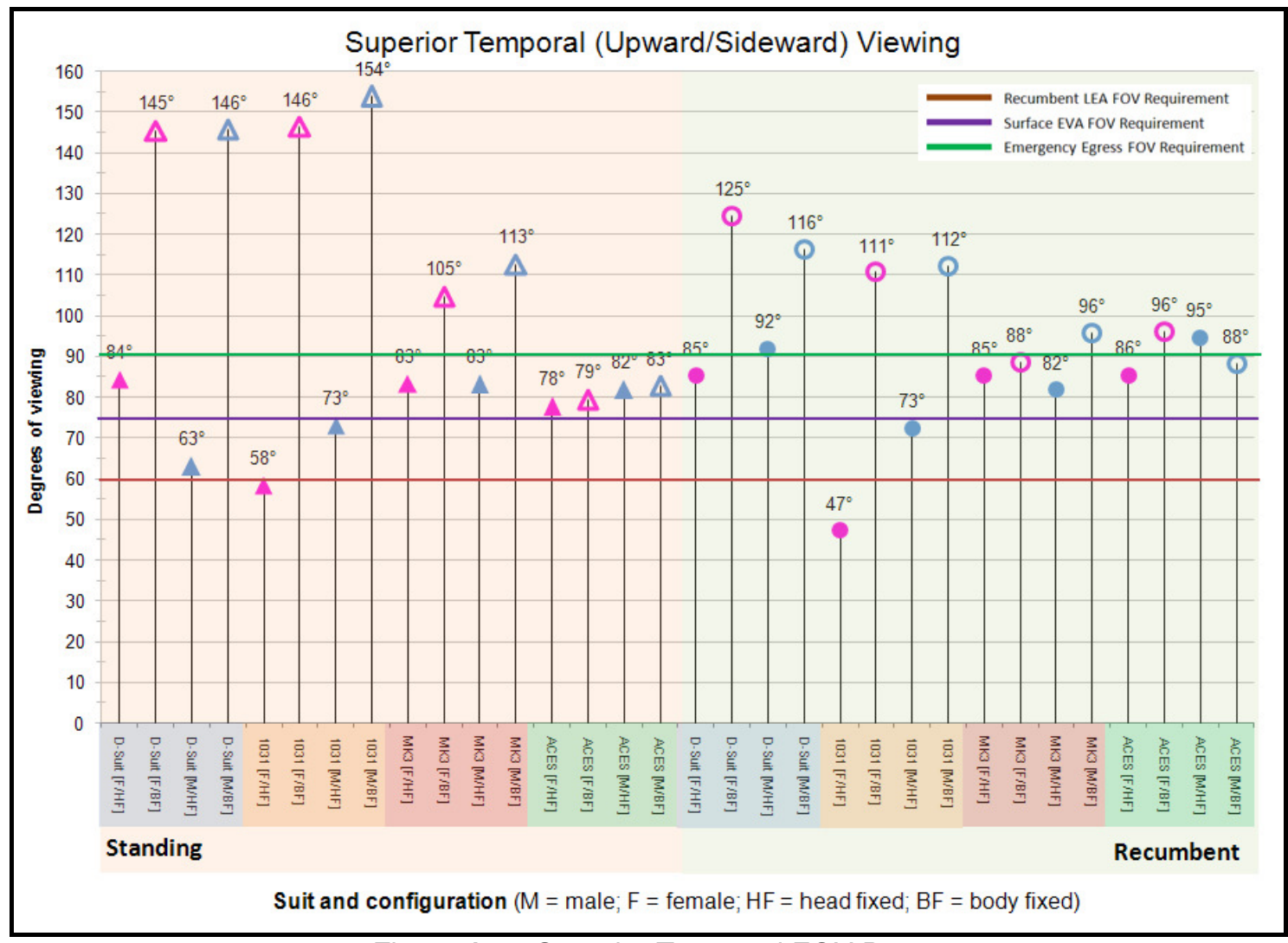

Figure A15: Superior Temporal FOV Data 


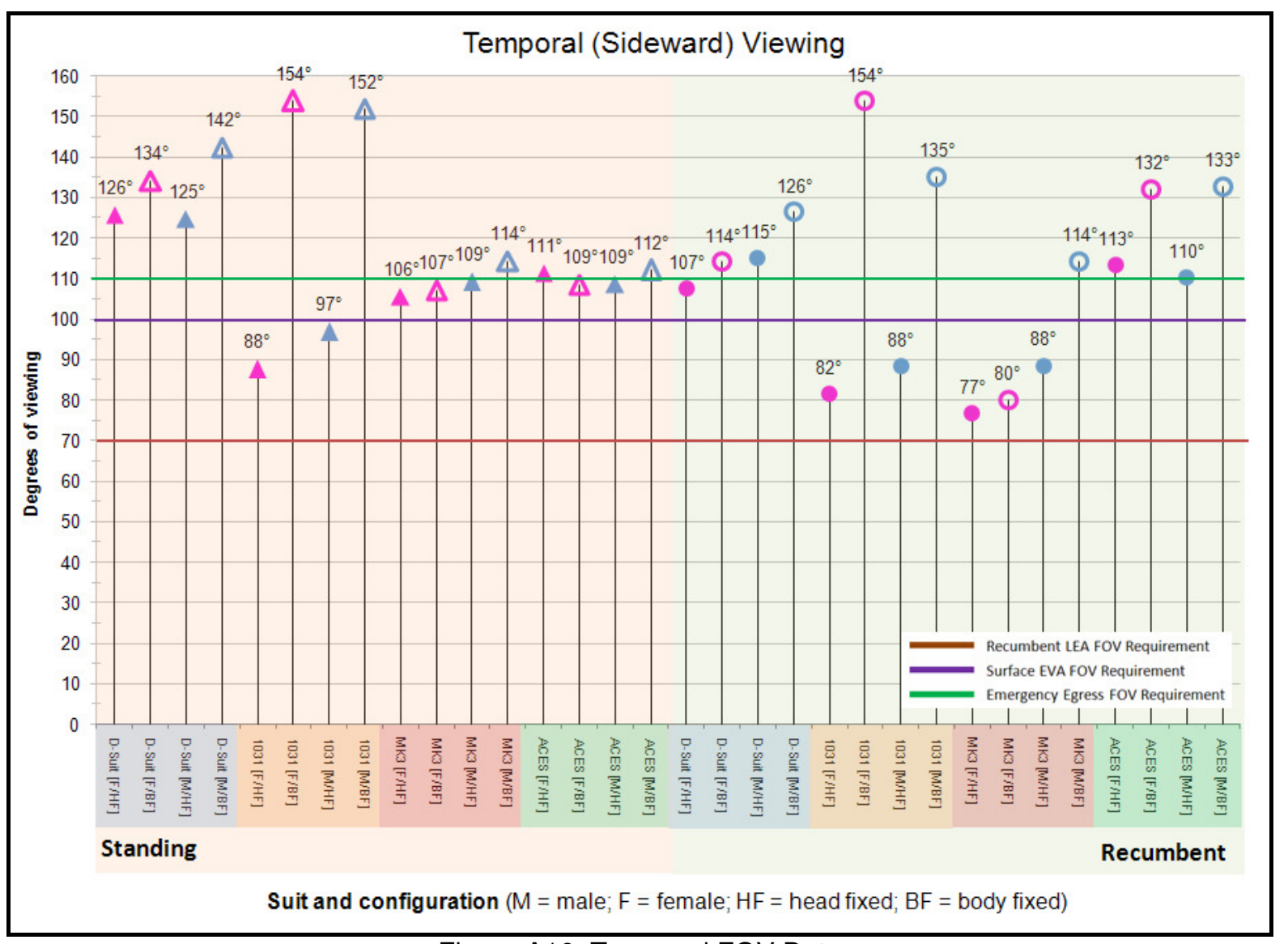

Figure A16: Temporal FOV Data

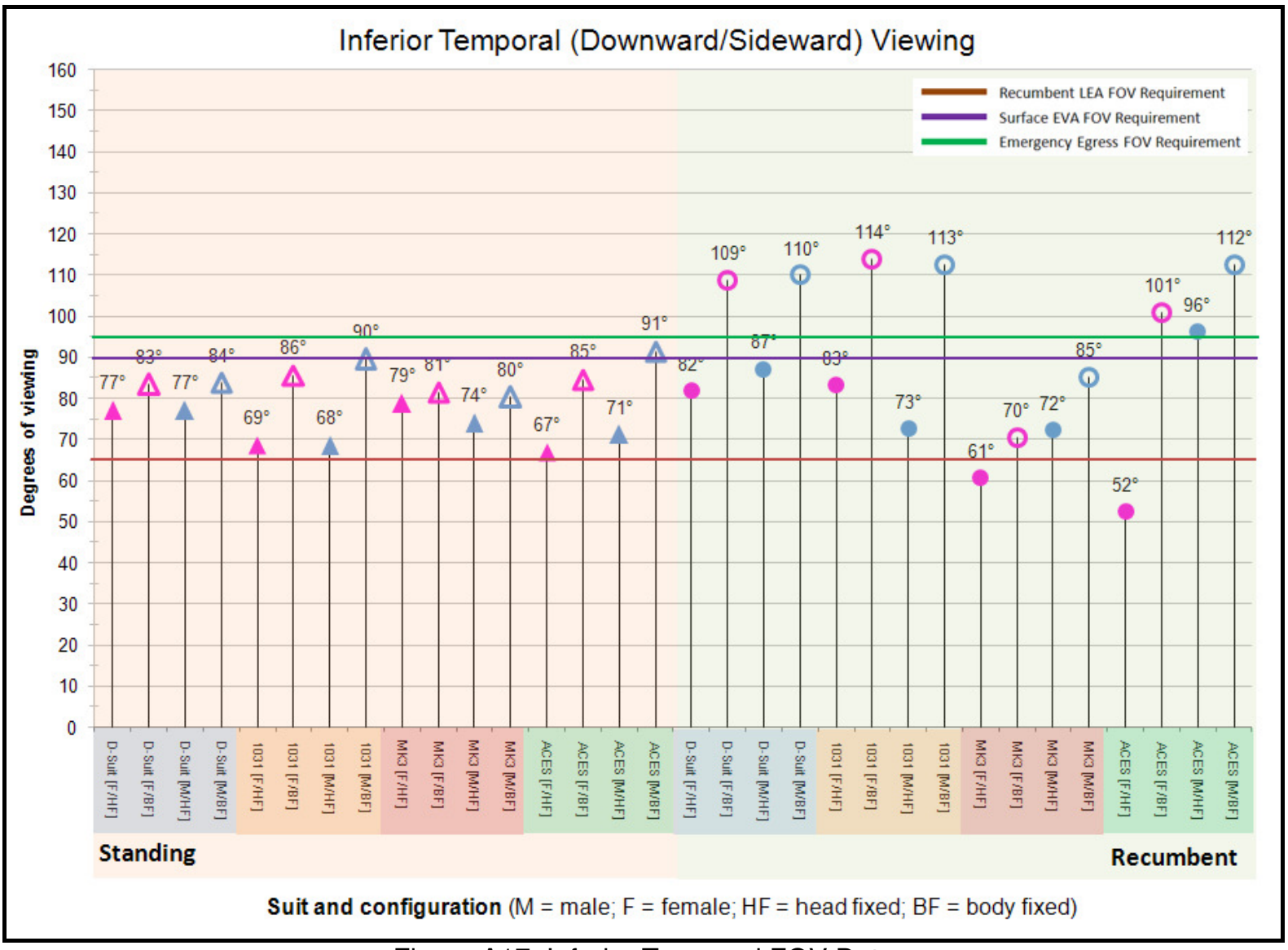

Figure A17: Inferior Temporal FOV Data 


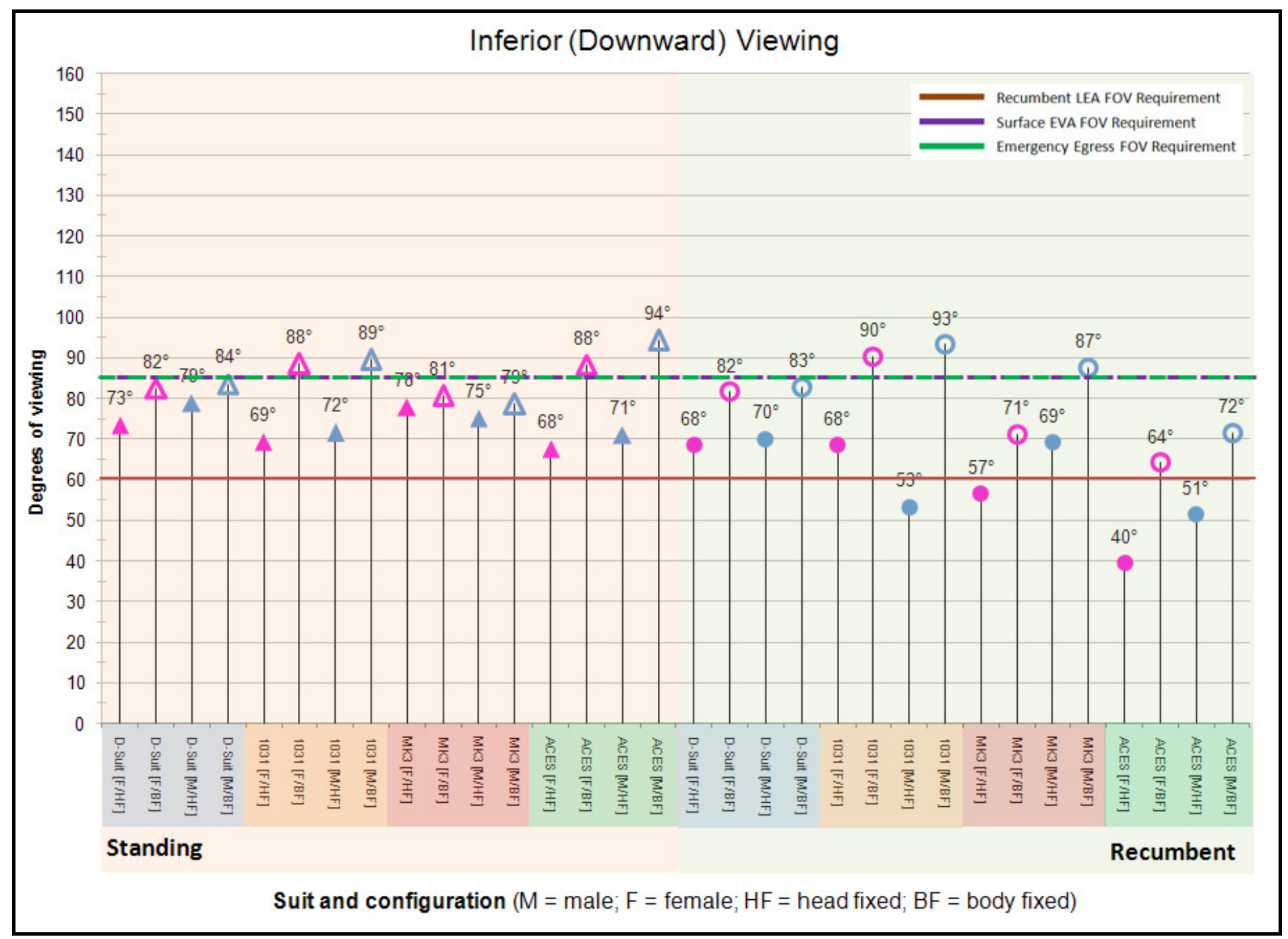

Figure A18: Inferior FOV Data 


\section{APPENDIX F: FIELD OF VIEW DELTAS BETWEEN SUBJECTS}

The chart below shows the field of view delta for each test point. The number given is the delta from the female subject to the male subject (for example, a positive green value of 5.0 indicates the male subject saw 5 degrees more than the female).

\begin{tabular}{|c|c|c|c|c|c|c|c|c|c|c|c|c|c|c|c|c|c|}
\hline \multirow{3}{*}{$\begin{array}{l}\text { Female to Male Delta } \\
\text { Body Position } \\
\text { Head Motion } \\
\end{array}$} & \multicolumn{4}{|c|}{ D-Suit } & \multicolumn{4}{|c|}{1031} & \multicolumn{4}{|c|}{ MK3 } & \multicolumn{4}{|c|}{ ACES } & \multirow{3}{*}{ AVG } \\
\hline & \multicolumn{2}{|c|}{ Standing } & \multicolumn{2}{|c|}{ Recumbent } & \multicolumn{2}{|c|}{ Standing } & \multicolumn{2}{|c|}{ Recumbent } & \multicolumn{2}{|c|}{ Standing } & \multicolumn{2}{|c|}{ Recumbent } & \multicolumn{2}{|c|}{ Standing } & \multicolumn{2}{|c|}{ Recumbent } & \\
\hline & $\mathrm{HF}$ & $\mathrm{BF}$ & $\mathrm{HF}$ & $\mathrm{BF}$ & $\mathrm{HF}$ & $\mathrm{BF}$ & $\mathrm{HF}$ & BF & $\mathrm{HF}$ & $\mathrm{BF}$ & $\mathrm{HF}$ & BF & $\mathrm{HF}$ & BF & $\mathrm{HF}$ & $\mathrm{BF}$ & \\
\hline Superior & -3.2 & -19.8 & -8.0 & -2.0 & +3.0 & +16.6 & +19.4 & +29.2 & -13.8 & -47.4 & -10.9 & -4.2 & -3.2 & +7.0 & +6.6 & +2.1 & -1.8 \\
\hline R Superior Temporal & -21.3 & +.2 & +6.8 & -8.2 & +14.8 & +7.4 & +25.1 & +1.4 & -.2 & +7.9 & -3.6 & +7.3 & +4.1 & +3.3 & +9.1 & -7.8 & +2.9 \\
\hline R Temporal & -1.0 & +8.2 & +7.6 & +12.3 & +9.2 & -1.9 & +6.7 & -18.7 & +3.5 & +7.2 & +11.8 & +34.1 & -2.8 & +3.5 & -3.0 & +.8 & +4.9 \\
\hline R Inferior Temporal & -.0 & +.4 & +5.4 & +1.2 & -.2 & +4.0 & -10.7 & -1.4 & -4.8 & -1.2 & +11.6 & +14.6 & +4.3 & +6.9 & +43.7 & +11.6 & +5.3 \\
\hline Inferior & +5.5 & +1.2 & +1.7 & +1.2 & +2.4 & +1.0 & -15.1 & +2.8 & -2.7 & -2.0 & +12.5 & +16.4 & +3.2 & +6.1 & +11.9 & +7.4 & +3.4 \\
\hline L Inferior Temporal & -.0 & +.4 & +5.4 & +1.2 & -.2 & +4.0 & -10.7 & -1.4 & -4.8 & -1.2 & +11.6 & +14.6 & +4.3 & +6.9 & +43.7 & +11.6 & +5.3 \\
\hline L Temporal & -1.0 & +8.2 & +7.6 & +12.3 & +9.2 & -1.9 & +6.7 & -18.7 & +3.5 & +7.2 & +11.8 & +34.1 & -2.8 & +3.5 & -3.0 & +.8 & +4.9 \\
\hline L Superior Temporal & -21.3 & +.2 & +6.8 & -8.2 & +14.8 & +7.4 & +25.1 & +1.4 & -.2 & +7.9 & -3.6 & +7.3 & +4.1 & +3.3 & +9.1 & -7.8 & +2.9 \\
\hline Individual Average & -5.3 & -.1 & +4.2 & +1.2 & +6.6 & +4.6 & +5.8 & -.7 & -2.4 & -2.7 & +5.2 & +15.5 & +1.4 & +5.1 & +14.8 & +2.3 & \\
\hline Suit/Position Average & \multicolumn{2}{|c|}{-2.7} & \multicolumn{2}{|c|}{+2.7} & \multicolumn{2}{|c|}{+5.6} & \multicolumn{2}{|c|}{+2.6} & \multicolumn{2}{|c|}{-2.6} & \multicolumn{2}{|c|}{+10.3} & \multicolumn{2}{|c|}{+3.2} & \multicolumn{2}{|c|}{+8.6} & \\
\hline Suit Average & \multicolumn{4}{|c|}{+.0} & \multicolumn{4}{|c|}{+4.1} & \multicolumn{4}{|c|}{+3.9} & \multicolumn{4}{|c|}{+5.9} & \\
\hline TOTAL AVERAGE & & & & & & & & & & & & & & & & & \\
\hline
\end{tabular}

Figure A19: Female to Male FOV Delta 
Standard deviation data for the collected data is presented below. The "Total Average" field in both charts represents the overall average standard deviation of both standing and recumbent data sets.

\begin{tabular}{|c|c|c|c|c|c|c|c|c|c|c|c|c|c|c|c|c|c|c|c|}
\hline \multirow{2}{*}{\multicolumn{2}{|c|}{$\begin{array}{l}\text { Standard Deviations of Data } \\
\mathrm{M}=\text { male; } \mathrm{F}=\text { female } \\
\mathrm{HF}=\text { head fixed; } \mathrm{BF}=\text { body fixed }\end{array}$}} & \multicolumn{16}{|c|}{ STANDING ${ }^{* *}$ STANDING ${ }^{* * *}$ STANDING ${ }^{* *}$ STANDING ${ }^{* *}$ STANDING $* *$ STANDING } & \multicolumn{2}{|c|}{ AVERAGES } \\
\hline & & \multirow{2}{*}{$\begin{array}{c}\text { D-Suit } \\
\text { [F/HF] } \\
1\end{array}$} & \multirow{2}{*}{$\begin{array}{c}\text { D-Suit } \\
{[\mathrm{F} / \mathrm{BF}]} \\
2\end{array}$} & \multirow{2}{*}{$\begin{array}{c}\text { D-Suit } \\
\text { [M/HF] } \\
3\end{array}$} & \multirow{2}{*}{$\begin{array}{c}\text { D-Suit } \\
\text { [M/BF] } \\
4\end{array}$} & \multirow{2}{*}{$\begin{array}{c}1031 \\
{[\mathrm{~F} / \mathrm{HF}]} \\
5\end{array}$} & \multirow{2}{*}{$\begin{array}{c}1031 \\
{[\mathrm{~F} / \mathrm{BF}]} \\
6\end{array}$} & \multirow{2}{*}{$\begin{array}{c}1031 \\
{[\mathrm{M} / \mathrm{HF}]} \\
7\end{array}$} & \multirow{2}{*}{$\begin{array}{c}1031 \\
{[\mathrm{M} / \mathrm{BF}]} \\
8\end{array}$} & \multirow{2}{*}{$\begin{array}{c}\mathrm{MK} 3 \\
{[\mathrm{~F} / \mathrm{HF}]} \\
9\end{array}$} & \multirow{2}{*}{$\begin{array}{c}\text { MK3 } \\
{[\mathrm{F} / \mathrm{BF}]} \\
10\end{array}$} & \multirow{2}{*}{$\begin{array}{c}\mathrm{MK} 3 \\
{[\mathrm{M} / \mathrm{HF}]} \\
11\end{array}$} & \multirow{2}{*}{$\begin{array}{c}\mathrm{MK3} \\
{[\mathrm{M} / \mathrm{BF}]} \\
12\end{array}$} & \multirow{2}{*}{$\begin{array}{c}\text { ACES } \\
{[\mathrm{F} / \mathrm{HF}]} \\
13\end{array}$} & \multirow{2}{*}{$\begin{array}{c}\text { ACES } \\
{[\mathrm{F} / \mathrm{BF}]} \\
14\end{array}$} & \multirow{2}{*}{$\begin{array}{c}\text { ACES } \\
{[\mathrm{M} / \mathrm{HF}]} \\
15\end{array}$} & \multirow{2}{*}{$\begin{array}{c}\text { ACES } \\
{[\mathrm{M} / \mathrm{BF}]} \\
16\end{array}$} & \multirow[t]{2}{*}{$\begin{array}{l}\text { Average } \\
\text { Standing }\end{array}$} & \multirow[t]{2}{*}{$\begin{array}{l}\text { Average } \\
\text { Recumbent }\end{array}$} \\
\hline FOV Angle Name & Ang & & & & & & & & & & & & & & & & & & \\
\hline Superior & 0 & 2.5 & 2.1 & 3.0 & 2.1 & 0.6 & 2.4 & 2.1 & 2.0 & 1.9 & 1.7 & 0.7 & 2.2 & 2.7 & 2.4 & 2.9 & 3.1 & 2.1 & \\
\hline R Superior Temporal & 45 & 1.4 & 1.7 & 1.4 & 3.2 & 3.0 & 1.6 & 2.5 & 1.9 & 1.7 & 1.2 & 2.3 & 2.2 & 2.6 & 2.4 & 3.5 & 3.5 & 2.3 & \\
\hline R Temporal & 90 & 2.4 & 4.5 & 2.2 & 4.8 & 2.0 & 2.1 & 0.0 & 3.3 & 4.8 & 2.5 & 2.9 & 1.4 & 2.5 & 0.8 & 2.3 & 1.6 & 2.5 & \\
\hline R Inferior Temporal & 135 & 0.9 & 0.3 & 1.1 & 0.2 & 1.6 & 0.3 & 0.8 & 0.5 & 0.4 & 0.3 & 0.4 & 0.1 & 0.4 & 0.9 & 0.8 & 0.4 & 0.6 & \\
\hline Inferior & 180 & 1.0 & 0.3 & 0.6 & 0.2 & 0.5 & 0.4 & 0.7 & 0.5 & 1.8 & 0.2 & 0.6 & 0.2 & 0.5 & 0.4 & 0.3 & 0.3 & 0.5 & \\
\hline L Inferior Temporal & 225 & 0.2 & 0.3 & 0.7 & 0.8 & 0.5 & 1.2 & 0.6 & 0.3 & 1.0 & 0.4 & 0.8 & 0.3 & 0.5 & 1.3 & 0.2 & 1.0 & 0.6 & \\
\hline L Temporal & 270 & 2.8 & 1.5 & 2.8 & 1.3 & 0.5 & 2.7 & 0.9 & 2.5 & 3.1 & 3.2 & 0.3 & 3.2 & 1.1 & 1.5 & 3.4 & 4.7 & 2.2 & \\
\hline L Superior Temporal & 315 & 2.7 & 4.4 & 0.7 & 1.2 & 1.8 & 1.1 & 2.3 & 1.8 & 1.8 & 3.5 & 2.0 & 2.9 & 1.3 & 0.5 & 2.2 & 3.6 & 2.1 & \\
\hline Individual Average & & 1.7 & 1.9 & 1.5 & 1.7 & 1.3 & 1.5 & 1.2 & 1.6 & 2.1 & 1.6 & 1.3 & 1.6 & 1.5 & 1.3 & 1.9 & 2.3 & & \\
\hline Average for suit/position & & \multicolumn{4}{|c|}{1.7} & \multicolumn{4}{|c|}{1.4} & \multicolumn{4}{|c|}{1.6} & \multicolumn{4}{|c|}{1.7} & & \\
\hline Body position Average & & \multicolumn{16}{|c|}{1.6} & & \\
\hline Total Average & & \multicolumn{16}{|c|}{1.7} & & \\
\hline
\end{tabular}

Figure A20: Standing Field of View Standard Deviations

\begin{tabular}{|c|c|c|c|c|c|c|c|c|c|c|c|c|c|c|c|c|c|c|c|}
\hline \multirow{2}{*}{\multicolumn{2}{|c|}{$\begin{array}{l}\text { Standard Deviations of Data } \\
M=\text { male; } F=\text { female } \\
H F=\text { head fixed; } B F=\text { body fixed }\end{array}$}} & \multicolumn{16}{|c|}{ RECUMBENT ** RECUMBENT ** RECUMBENT ** RECUMBENT ** RECUMBENT ** RECUMBENT } & \multicolumn{2}{|c|}{ AVERAGES } \\
\hline & & \multirow{2}{*}{$\begin{array}{c}\text { D-Suit } \\
\text { [F/HF] } \\
17\end{array}$} & \multirow{2}{*}{$\begin{array}{c}\text { D-Suit } \\
\text { [F/BF] } \\
18\end{array}$} & \multirow{2}{*}{$\begin{array}{c}\text { D-Suit } \\
{[\mathrm{M} / \mathrm{HF}]} \\
19\end{array}$} & \multirow{2}{*}{$\begin{array}{c}\text { D-Suit } \\
{[\mathrm{M} / \mathrm{BF}]} \\
20\end{array}$} & \multirow{2}{*}{$\begin{array}{c}1031 \\
{[\mathrm{~F} / \mathrm{HF}]} \\
21\end{array}$} & \multirow{2}{*}{$\begin{array}{c}1031 \\
{[\mathrm{~F} / \mathrm{BF}]} \\
22\end{array}$} & \multirow{2}{*}{$\begin{array}{c}1031 \\
{[\mathrm{M} / \mathrm{HF}]} \\
23\end{array}$} & \multirow{2}{*}{$\begin{array}{c}1031 \\
{[\mathrm{M} / \mathrm{BF}]} \\
24\end{array}$} & \multirow{2}{*}{$\begin{array}{c}\text { MK3 } \\
{[\mathrm{F} / \mathrm{HF}]} \\
25\end{array}$} & \multirow{2}{*}{$\begin{array}{c}\text { MK3 } \\
{[\mathrm{F} / \mathrm{BF}]} \\
26\end{array}$} & \multirow{2}{*}{$\begin{array}{c}\text { MK3 } \\
{[\mathrm{M} / \mathrm{HF}]} \\
27\end{array}$} & \multirow{2}{*}{$\begin{array}{c}\text { MK3 } \\
{[\mathrm{M} / \mathrm{BF}]} \\
28\end{array}$} & \multirow{2}{*}{$\begin{array}{c}\text { ACES } \\
{[\mathrm{F} / \mathrm{HF}]} \\
29\end{array}$} & \multirow{2}{*}{$\begin{array}{c}\text { ACES } \\
{[\mathrm{F} / \mathrm{BF}]} \\
30\end{array}$} & \multirow{2}{*}{$\begin{array}{c}\text { ACES } \\
{[\mathrm{M} / \mathrm{HF}]} \\
31\end{array}$} & \multirow{2}{*}{$\begin{array}{c}\text { ACES } \\
{[\mathrm{M} / \mathrm{BF}]} \\
32\end{array}$} & \multirow[t]{2}{*}{$\begin{array}{l}\text { Average } \\
\text { Standing }\end{array}$} & \multirow[t]{2}{*}{$\begin{array}{l}\text { Average } \\
\text { Recumbent }\end{array}$} \\
\hline Fov Angle Name & Ang & & & & & & & & & & & & & & & & & & \\
\hline Superior & 0 & 2.1 & 2.6 & 2.7 & 2.0 & 1.2 & 4.7 & 0.9 & 0.4 & 1.8 & 3.5 & 0.5 & 4.3 & 3.4 & 0.6 & 4.5 & 0.6 & & 2.2 \\
\hline R Superior Temporal & 45 & 4.1 & 0.4 & 3.3 & 0.8 & 1.6 & 0.4 & 0.8 & 0.6 & 1.6 & 2.0 & 1.8 & 4.3 & 1.6 & 2.2 & 2.3 & 2.1 & & 1.9 \\
\hline R Temporal & 90 & 1.2 & 0.2 & 0.4 & 1.7 & 0.5 & 2.1 & 1.3 & 2.1 & 5.9 & 1.8 & 0.3 & 0.3 & 1.4 & 1.5 & 1.0 & 0.5 & & 1.4 \\
\hline R Inferior Temporal & 135 & 0.3 & 0.4 & 0.6 & 0.2 & 0.3 & 2.7 & 0.4 & 3.6 & 0.6 & 2.7 & 0.2 & 0.5 & 4.4 & 4.1 & 1.5 & 0.3 & & 1.4 \\
\hline Inferior & 180 & 0.5 & 0.2 & 1.8 & 0.1 & 0.2 & 1.7 & 0.4 & 0.4 & 2.2 & 2.7 & 0.7 & 0.4 & 3.8 & 4.9 & 1.0 & 0.4 & & 1.3 \\
\hline L Inferior Temporal & 225 & 0.3 & 2.5 & 0.7 & 2.1 & 0.5 & 1.0 & 1.0 & 4.1 & 0.4 & 3.0 & 0.9 & 0.7 & 3.0 & 3.7 & 2.9 & 2.5 & & 1.8 \\
\hline L Temporal & 270 & 0.7 & 1.5 & 9.8 & 1.7 & 0.5 & 2.7 & 1.8 & 2.1 & 2.4 & 1.3 & 1.5 & 0.4 & 1.0 & 1.5 & 3.4 & 0.5 & & 2.0 \\
\hline L Superior Temporal & 315 & 0.4 & 0.4 & 2.6 & 3.2 & 2.3 & 2.3 & 1.2 & 1.0 & 0.5 & 1.0 & 1.1 & 3.9 & 3.2 & 4.0 & 1.6 & 1.1 & & 1.9 \\
\hline Individual Average & & 1.2 & 1.0 & 2.7 & 1.5 & 0.9 & 2.2 & 1.0 & 1.8 & 1.9 & 2.2 & 0.9 & 1.8 & 2.7 & 2.8 & 2.3 & 1.0 & & \\
\hline Average for suit/position & & \multicolumn{4}{|c|}{1.6} & \multicolumn{4}{|c|}{1.5} & \multicolumn{4}{|c|}{1.7} & \multicolumn{4}{|c|}{2.2} & & \\
\hline Body position Average & & \multicolumn{16}{|c|}{1.7} & & \\
\hline Total Average & & \multicolumn{16}{|c|}{1.7} & & \\
\hline
\end{tabular}

Figure A21: Recumbent Field of View Standard Deviations

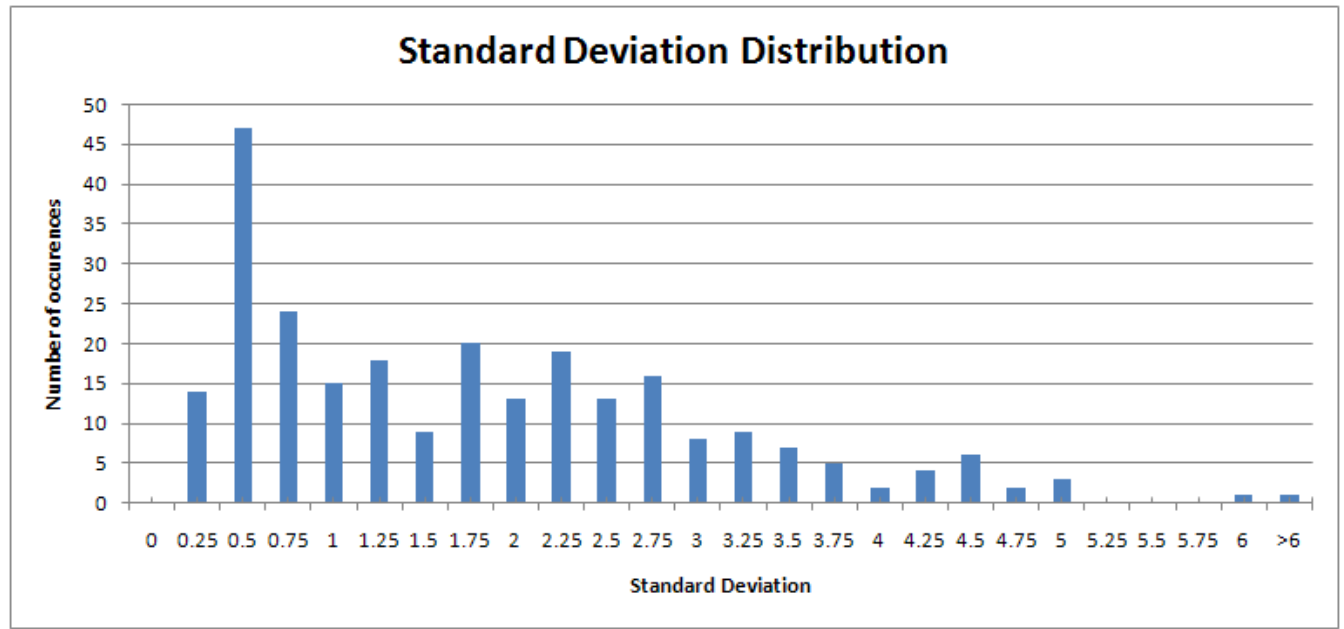

Figure A22: Field of View Data Standard Deviation Distribution 